$$
\begin{gathered}
\text { UNIVERSIDADE DE BRASÍLIA } \\
\text { FACULDADE DE EDUCAÇÃO FÍSICA } \\
\text { PROGRAMA DE PÓS-GRADUAÇÃO STRICTO-SENSU EM } \\
\text { EDUCAÇÃO FÍSICA }
\end{gathered}
$$

\title{
ANÁLISE DE PARÂMETROS ELETROMIOGRÁFICOS DURANTE EXERCÍCIO REALIZADO COM RESISTÊNCIA ELÁSTICA SOB CONTROLE OBJETIVO OU SUBJETIVO
}

Fernanda Sampaio Teles

BRASÍLIA 
ANÁLISE DE PARÂMETROS ELETROMIOGRÁFICOS DURANTE EXERCÍCIO REALIZADO COM RESISTÊNCIA ELÁSTICA SOB CONTROLE OBJETIVO OU SUBJETIVO

\author{
FERNANDA SAMPAIO TELES
}

Dissertação apresentada à

Faculdade de Educação Física da Universidade de Brasília, como requisito parcial para a obtenção do grau de Mestre em Educação Física. 


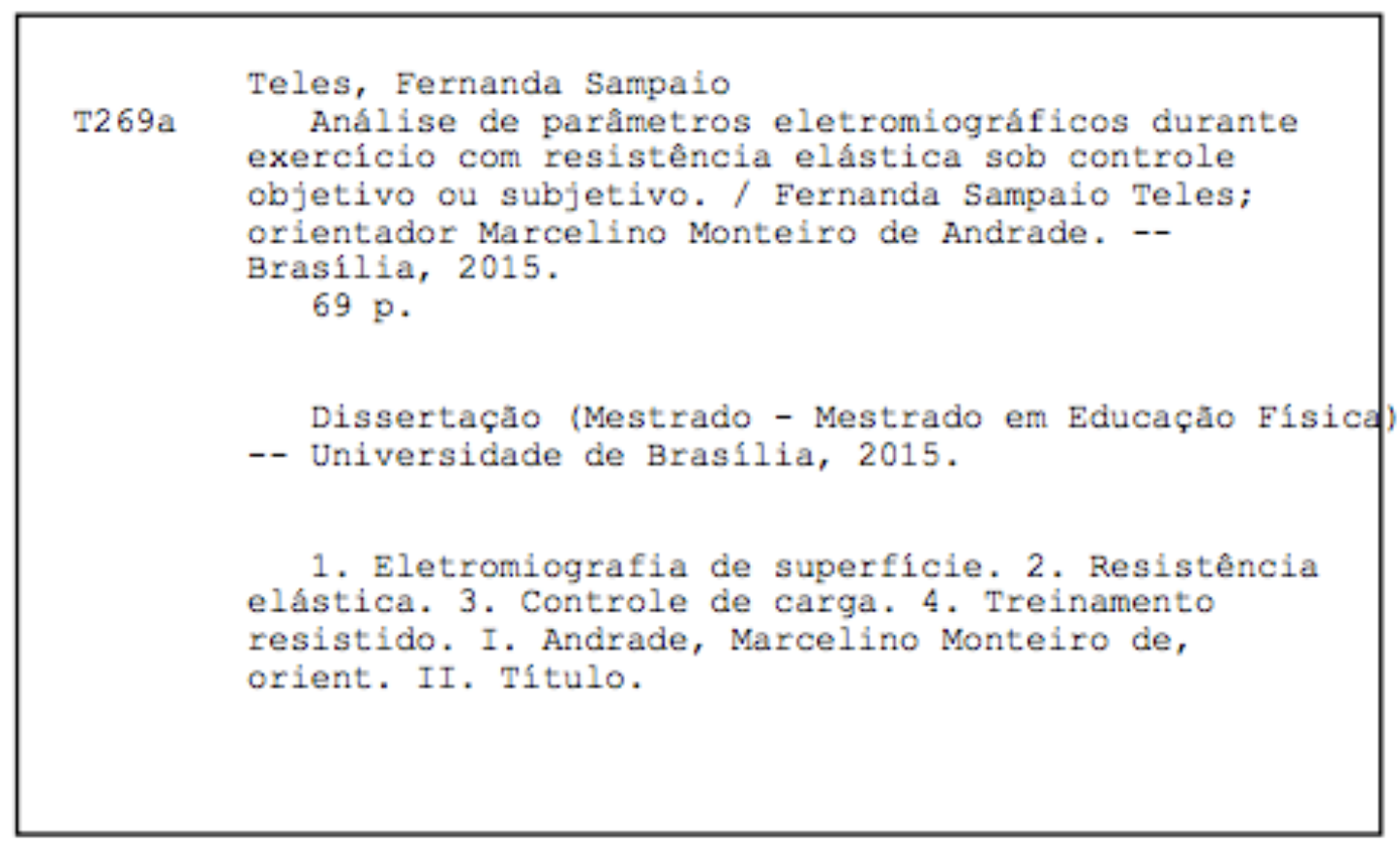

\section{REFERÊNCIA BIBLIOGRÁFICA}

TELES, Fernanda Sampaio. Análise de parâmetros eletromiográficos durante exercício realizado com resistência elástica sob controle objetivo ou subjetivo. Universidade de Brasília, Faculdade de Educação Física, 2015. 69p. Dissertação apresentada à Faculdade de Educação Física da Universidade de Brasília, como requisito parcial para a obtenção de grau de Mestre em Educação Física.

\section{CESSÃO DE DIREITOS}

Autor: Fernanda Sampaio Teles

Título: Análise de parâmetros eletromiográficos durante exercício realizado com resistência elástica sob controle objetivo ou subjetivo.

\section{GRAU: Mestre ANO: 2015}

É concedida à Universidade de Brasília permissão para reproduzir cópias desta dissertação e para emprestar ou vender tais cópias somente para propósitos acadêmicos e científicos. O autor reserva outros direitos de publicação e nenhuma parte dessa dissertação de mestrado pode ser reproduzida sem autorização por escrito do autor.

Fernanda Sampaio Teles

SQS 307 bloco K apartamento 202

70354-110 Brasília - DF - Brasil 


\section{ANÁLISE DE PARÂMETROS ELETROMIOGRÁFICOS DURANTE EXERCÍCIO REALIZADO COM RESISTÊNCIA ELÁSTICA SOB CONTROLE OBJETIVO OU SUBJETIVO.}

Dissertação aprovada como requisito parcial para obtenção do título de Mestre em Educação Física pelo Programa de Pós-Graduação da Faculdade de Educação Física da Universidade de Brasília.

Banca examinadora:

Prof. Dr. Marcelino Monteiro de Andrade (Orientador - FEF/UnB)

Prof. Dr. Jake Carvalho do Carmo

(Examinador Interno - FEF/UnB)

Prof. Dr. Antônio Padilha Lanari Bó

(Examinador Externo - ENE/UnB)

Brasília - DF, 10 de Julho de 2015 


\section{AGRADECIMENTOS}

"The world as we have created it is a process of our thinking. It cannot be changed without changing our thinking."

Albert Einstein

Agradeço a oportunidade em cursar uma especialização stricto-sensu e assim vivenciar experiências únicas de forma a colaborar com o conhecimento acadêmico, social e profissional.

Aos meus pais, Vitória Elizabeth Sampaio Bastos e Sidnei Ribeiro Teles que me proporcionaram a melhor formação possível além de todo apoio em minhas decisões; e a todos meus familiares que sempre torceram por mim.

Aos meus grandes orientadores, professores e amigos Marcelino Monteiro de Andrade e Jake Carvalho do Carmo os quais me acompanham durante a minha carreira acadêmica e permitem vivências cujos ensinamentos transcendem aqueles necessários para obtenção desse título. À eles, dedico toda essa obra.

Aos amigos sempre presentes nos momentos de conquistas, coletas, dificuldades e que nunca negaram alguma forma de ajuda quando houve imprevistos, Gabriela Sartório Barbosa, Maria Cláudia Cardoso Pereira, Valdinar de Araújo Rocha Júnior, Filipe Barreto Tomé e David Fiorillo. Com eles compartilho os méritos da conclusão da dissertação.

A todos os funcionários e corpo docente da Faculdade de Educação Física, Faculdade de Tecnologia e Faculdade do Gama da Universidade de Brasília por cuidarem durante esses anos do meu ambiente de trabalho e agregarem valor a minha formação e crescimento acadêmico.

Aos voluntários da pesquisa pela disponibilidade, compromisso e seriedade na realização dos testes.

A todos os meus amigos que tiveram participação indireta no mestrado mas que nunca deixaram de me acompanhar, apoiar e incentivar durante esses anos. 
Página

LISTA DE TABELAS ..................................................................... iii

LISTA DE FIGURAS .......................................................... iv

LISTA DE SIGLAS, ABREVIAÇÕES E SÍMBOLOS................................. v

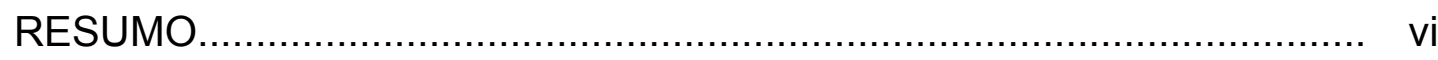

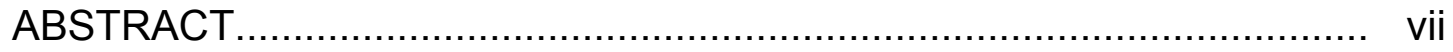

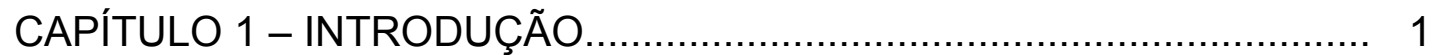

1.1 - Objetivo............................................................................ 2

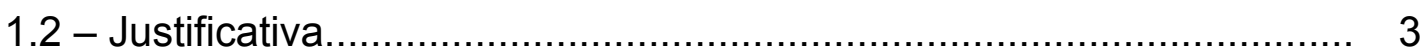

CAPÍTULO 2 - REVISÃO DE LITERATURA ………............................ 5

2.1 - Métodos Resistivos e Controle de Carga........................................ 5

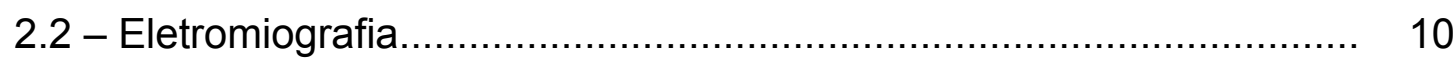

CAPÍTULO 3 - MATERIAIS E MÉTODOS............................................. 19

3.1 - Amostra

3.2 - Introdução aos Protocolos Experimentais....................................... 19

3.3 - Descrição dos Protocolos Experimentais......................................... 20

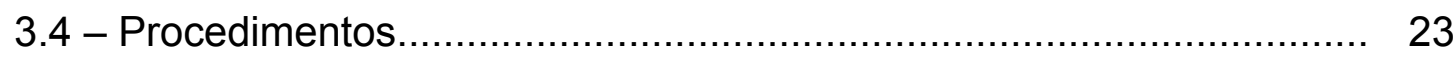

3.4.1 - Célula de Carga e Eletrogoniômetro.......................................... 23

3.4.2 - Avaliação Antropométrica........................................................ 24

3.4.3 - Contração Voluntária Isométrica Máxima...................................... 24

3.4.4 - Dispositivo de Biofeedback ................................................... 25

3.4.5 - Equipamento de Resistência Elástica...................................... 27

3.4.6 - Aquisição dos Sinais de Eletromiografia...................................... 28

3.4.7 - O Processamento dos Sinais..................................................... 28

3.5 - Análise Estatística...................................................................... 29

CAPÍTULO 4 - RESULTADOS............................................................. 31

CAPÍTULO 5 - DISCUSSÃO................................................................. 35

CAPÍTULO 6 - CONCLUSÕES ..................................................... 43

REFERÊNCIAS BIBLIOGRÁFICAS................................................... 44

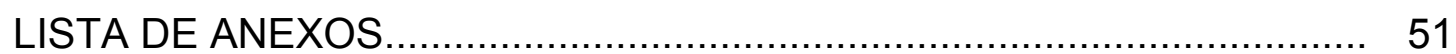




\section{LISTA DE TABELAS}

Página

Tabela 1 - Resumo das comparações estatísticas realizadas intra- 30 grupos.

Tabela 2 - Descrição dos participantes que compuseram a amostra....... 31 


\section{LISTA DE FIGURAS}

Página

Figura 1 - Variação do raio de um maquinário para o exercício "pullover" (McMaster et al., 2009).

Figura 2 - OMNI resistance exercise scale of perceived exertion para uso com bandas elásticas (Colado et al. 2012).

Figura 3 - Representação da amplificação diferencial de um eletrodo bipolar.

Figura 4 - Alteração do sinal da amplitude e espectro de frequência do SEMG com a variação da colocação do eletrodo (modificado - De Luca, 1997).

Figura 5 - Sinal eletromiográfico bruto e retificado por onda completa 16 (Marchetti et al., 2006)

Figura 6 - Tarefas na polia (TRDp) e com resistência elástica (TRDi) do Grupo Tradicional (GTRD), respectivamente.

Figura 7 - Diagrama dos Protocolos Experimentais da pesquisa.

Figura 8 - Aquisição da contração voluntária isométrica máxima (CVIM)

Figura 9 - Equipamento de controle de carga para resistência elástica com biofeedback ajustado para as tarefas feitas com implemento elástico no GBIO.

Figura 10 - Kit de elásticos e acessórios da marca Elastos ${ }^{\circledR}$ utilizados no presente estudo.

Figura 11 - Representação do recorte do sinal eletromiográfico com base nas informações do eletrogoniômetro.

Figura 12 - Gráfico Bland and Altman com os valores da FPMd das tarefas polia e início do grupo GBIO.

Figura 13 - Gráfico Bland and Altman com os valores da FPMd das tarefas polia e meio do grupo GBIO.

Figura 14 - Gráfico Bland and Altman com os valores da FPMd das tarefas polia e início do grupo GTRD.

Figura 15 - Gráfico Bland and Altman com os valores da FPMd das tarefas polia e meio do grupo GTRD. 
SEMG Eletromiografia de Superfície

EMG Eletromiografia

RMS Root Mean Square (Raiz do Valor Médio Quadrático)

FPMd Frequência de Potência Mediana

FPM Frequência de Potência Média

FML Fadiga Muscular Localizada

PSE Escala de Percepção Subjetiva de Esforço

TR Treinamento Resistido

OMNI-RES Adult OMNI Perceived Exertion Scale for Resistance Exercise

SENIAM Surface ElectroMyoGraphy for the Non-Invasive Assessment of Muscles

CVIM Contração Voluntária Isométrica Máxima

GBIO Grupo Biofeedback

GTRD Grupo Tradicional

BIOi Tarefa Biofeedback Início (controle objetivo de carga)

BIOm Tarefa Biofeedback Meio (controle objetivo de carga)

TRDi Tarefa Tradicional Início (controle subjetivo de carga)

TRDm Tarefa Tradicional Meio (controle subjetivo de carga)

BIOp Tarefa Polia do Grupo Biofeedback

TRDp Tarefa Polia do Grupo Tradicional

CEP Comitê de Ética em Pesquisa

INPI Instituto Nacional da Propriedade Industrial

FUB Fundação Universidade de Brasília

TCLE Termo de Consentimento Livre e Esclarecido

RM Repetição Máxima

ARV Average Rectified Value 


\section{RESUMO}

\section{ANÁLISE DE PARÂMETROS ELETROMIOGRÁFICOS DURANTE EXERCÍCIO REALIZADO COM RESISTÊNCIA ELÁSTICA SOB CONTROLE OBJETIVO OU SUBJETIVO DE CARGA}

\section{Autora: Fernanda Sampaio Teles}

Orientador: Marcelino Monteiro de Andrade

O objetivo do presente estudo foi analisar o comportamento de parâmetros eletromiográficos durante o exercício de flexão de cotovelo realizado com resistência elástica sob controle objetivo ou subjetivo de carga. O sinal eletromiográfico de superfície foi registrado, por um eletrodo bipolar, no músculo bíceps braquial de 31 indivíduos do sexo masculino $(29,03 \pm 5,99$ anos, $81,81 \pm 8,65 \mathrm{~kg}, 179,09 \pm 5,05 \mathrm{~cm}$ ) praticantes de treinamento resistido. Os sujeitos realizaram duas contrações voluntárias isométricas máximas (CVIM) com o cotovelo a 90 graus e alocados, de forma contrabalanceada, ou no grupo com biofeedback (GBIO) ou no grupo com controle subjetivo de carga (GTRD). Todos os sujeitos realizaram três tarefas com diferentes resistências (polia e elástico). As tarefas consistiam em doze repetições unilaterais de flexão do cotovelo a $30 \%$ da CVIM. Essa intensidade foi utilizada durante o exercício na polia, com resistência elástica ao iniciar o movimento e com resistência elástica ao atingir a metade do movimento. As variáveis eletromiográficas foram comparadas através de ANOVAs fatoriais de delineamento misto. Para o RMS, houve interação entre os grupos e efeitos principais entre as tarefas. Não houve diferenças significativas entre as tarefas do GBIO. Foram encontradas diferenças significativas nas tarefas que utilizaram resistência elástica comparadas com a polia no GTRD. Para FPMd, não houve interação nem efeitos principais. O procedimento de Bland e Altman (1983) confirmou uma excelente concordância entre todas as tarefas para FPMd. A ativação muscular foi significativamente modificada quando o exercício foi realizado sem controle objetivo de carga durante flexão de cotovelo com resistência elástica.

Palavras-chave: eletromiografia de superfície, resistência elástica, controle de carga. 


\title{
ABSTRACT \\ ANALYSIS OF THE ELECTROMYOGRAPHY PARAMETERS DURING EXERCISE PERFORMED WITH ELASTIC RESISTANCE AND OBJECTIVE OR SUBJECTIVE LOAD CONTROL
}

\author{
Autora: Fernanda Sampaio Teles \\ Orientador: Marcelino Monteiro de Andrade
}

The purpose of this study was to analyze the electromyography parameters during elbow flexions performed with elastic resistance and objective or subjective load control. Surface electromyography of the biceps brachii was registered with a bipolar electrode of thirty one resistance trained males $(29,03 \pm 5,99 \mathrm{yr}, 81,81 \pm 8,65 \mathrm{~kg}, 179,09 \pm 5,05 \mathrm{~cm})$. They performed 2 maximal isometric (MVC) unilateral elbow flexions at $90^{\circ}$ of flexion and they were assigned, in counterbalanced order, to a group with biofeedback (GBIO) or a group with subjective control of load (GTRD). All volunteers performed three tasks with different types of resistance (pulley and elastic). Tasks consisted in twelve unilateral elbow flexions with $30 \%$ of MVC. This same load was used during exercises performed with pulley, at the beginning of the movement with elastic resistance and reaching it in the middle of the movement with elastic resistance. Electromyography parameters were compared using mixed-design ANOVAs. For RMS, there was interaction for groups and main effect for tasks. There were no significant differences between tasks in GBIO. There were significant differences between tasks performed with elastic resistance compared to pulley in GTRD. For MDF, there were no interaction or main effects. The Bland-Altman procedure confirmed an excellent concordance between all tasks for MDF. Muscular activation was significantly modified when exercise was performed without objective load control during elbow flexion with elastic resistance.

Keywords: surface electromyography, elastic resistance, load control. 


\section{CAPÍTULO 1 - INTRODUÇÃO}

O treinamento resistido (TR) é comumente utilizado como estratégia para desenvolvimento de capacidades físicas e praticado por diversas populações. Variedades de tecnologias são utilizadas para possibilitar a prática do treinamento físico de acordo com o objetivo a ser almejado (Fleck \& Kraemer, 2006).

Exercícios realizados com pesos livres, polias ou maquinário de musculação possuem resistência constante, podendo sofrer variações na velocidade de execução, número de repetições, diferentes ações musculares, dentre outras. Já exercícios praticados com resistência variável, como elásticos, apresentam variações de carga no decorrer da execução do movimento (Fleck \& Kraemer, 2006). Apesar da variação de intensidade, os elásticos possuem características singulares quando comparados aos equipamentos de carga constante. Estes conciliam praticidade, portabilidade e baixo custo. No entanto, a literatura carece de estudos que tenham comparado exercícios realizados com implementos elásticos e com carga constante.

Além dos poucos estudos sobre a resistência elástica, a dificuldade em se obter um procedimento metodológico capaz de permitir um comparativo entre os tipos de resistências a serem usadas e as consequências fisiológicas para cada intervenção, torna o uso de implementos elásticos restrito e voltado para programas de reabilitação articular ou clínicos, onde os exercícios são realizados, na maioria das vezes, com intensidades submáximas (Andersen et al. 2010, Colado et al., 2011). Segundo Andersen et al. (2010) apenas alguns estudos analisaram adaptações fisiológicas induzidas por exercícios com resistência elástica comparados a outras modalidades de contração. Além disso, estudos anteriores verificaram que o uso de resistência elástica em intensidade adequada proporciona melhoras significativas em testes funcionais e provoca mudanças na composição corporal com diminuição da perimetria abdominal e percentual de gordura corporal (Colado et al. 2008, 2009).

Apesar das evidências a favor da resistência elástica, grande parte dos materiais existentes hoje não determinam objetivamente qual a intensidade dos exercícios. Por conseguinte, para controlar o nível de intensidade, são utilizadas escalas de percepção subjetiva de esforço (PSE). Colado e seus colaboradores 
(2012) validaram uma escala desse tipo para tal finalidade. Nessa pesquisa o aumento progressivo da PSE durante exercício com resistência elástica esteve diretamente relacionado às adaptações fisiológicas agudas e crescentes no sistema muscular e cardíaco. Mesmo sabendo dos benefícios ao se utilizar uma escala de PSE, a falta de um método de controle quantitativo e direto da intensidade dos exercícios com elásticos não permite estabelecer relações claras de dose-efeito, tal como já foi demonstrado por meta-análises do TR com pesos e polias (Steib et al., 2010; Peterson et al., 2010).

A eletromiografia de superfície (SEMG) tem sido um método comumente utilizado para avaliar a ativação eletromiográfica relacionada à intensidade do exercício físico. Sabe-se que a utilização da SEMG pode fornecer informações relevantes sobre o recrutamento de unidades motoras (Bonato et al., 1996) bem como o comportamento da fadiga muscular localizada (Gerleman et al. 1989). Além disso, a atividade elétrica muscular no TR pode comprovar benefícios, potencializar os resultados ou corrigir eventuais falhas dos métodos já existentes (Rocha Júnior, 2008). Alguns autores fizeram uso dessa ferramenta, agregando valor à discussão acerca do comportamento neuromuscular durante exercícios com diferentes tipos de resistências (Cannon et al., 2007; Melchiorri et al., 2011; Calatayud et al. 2015).

Tendo em vista essa problemática, a criação de métodos e protocolos específicos baseados em evidências científicas para controle fidedigno de intensidade durante exercícios com elásticos se torna de fundamental importância.

\subsection{0bjetivo}

O objetivo do presente estudo foi analisar o comportamento de parâmetros eletromiográficos durante o exercício de flexão de cotovelo realizado com resistência elástica sob controle objetivo ou subjetivo de carga. Buscou-se verificar se o uso do biofeedback e controle de carga objetivo modificam o padrão de ativação e fadiga muscular durante a flexão de cotovelo em comparação com o uso de resistência constante e variável com controle de intensidade subjetivo, ou seja, baseado na percepção de esforço. 


\subsection{Justificativa}

Os últimos consensos sobre treinamento resistido apontam para a eficácia dos maquinários e pesos livres com a finalidade de melhorar variáveis da função muscular e composição corporal (ACSM 2009; Steib et al., 2010; Peterson et al., 2010). Estudos com resistência elástica também já demonstraram desfechos benéficos para variáveis da função muscular em diferentes populações (Colado et al. 2008; Colado et al. 2010; Melchiorri et al., 2011, Martins, 2013; Calatayud et al. 2015).

No entanto, existe uma carência na literatura de estudos que tenham comparado exercícios realizados com resistência constante à exercícios realizados com resistência variável. Tal fato pode estar relacionado à dificuldade em se estabelecer um consenso metodológico sobre o controle de carga com uso de resistência variável. Normalmente, os protocolos de intervenção tentam fazer esse controle de forma qualitativa, isto é, por meio de escalas de percepção subjetiva de esforço (Colado et al., 2012) ou até mesmo utilizam elásticos com diferentes informações dos níveis de resistências fornecidas pelos próprios fabricantes (Martins et al., 2013).

Sabe-se que o comportamento do recrutamento das unidades motoras mensuradas através da eletromiografia de superfície pode fornecer informações sobre os ganhos nas capacidades musculares em diferentes populações (Cannon et al., 2007; Melchiorri et al., 2011). Essa ferramenta pode contribuir de forma significativa no aprofundamento do conhecimento a respeito da necessidade de controlar a carga de treinamento, pois segundo Gerleman et al. (1989) a SEMG permite analisar as relações entre o sinal eletromiográfico e a produção de força.

Face ao exposto, o presente estudo propôs uma metodologia na qual a intensidade de exercícios praticados com resistência elástica foi controlada por meio de transdutores de força e biofeedback, para garantir um controle quantitativo de intensidade durante o exercício físico. Não é do nosso conhecimento que parâmetros eletromiográficos de amplitude e frequência tenham sido estudados durante exercícios que utilizaram dispositivos quantitativos de controle de carga para resistência elástica. Uma correta manipulação da intensidade em elásticos pode transformar tais 
implementos em uma eficaz alternativa para praticantes de TR em diversas populações, reforçando sua portabilidade e agregando resultados positivos para o desenvolvimento de capacidades físicas (Colado et al. 2008, 2010; Melchiorri et al., 2011; Calatayud et al. 2015). 


\section{CAPÍTULO 2 - REVISÃO DE LITERATURA}

\subsection{Métodos Resistivos e Controle de Carga}

O treinamento resistido pode ser definido como a prática de exercícios que promovem movimentos de segmentos corporais contra uma determinada força geralmente exercida por algum tipo de equipamento (Fleck \& Kraemer, 2006). As primeiras pesquisas científicas surgiram no final da década de 40 quando os autores Delmore e Watkins escreveram sobre os exercícios de força com intensidade progressiva na reabilitação de militares no período pós-guerra (Kraemer et al., 2002).

A aplicação do treinamento resistido requer a elaboração de um programa de treinamento que é considerada uma tarefa complexa pois exige um conhecimento e controle das variáveis que influenciam o desempenho do praticante baseando-se no objetivo a ser almejado (Tan, 1999). Com a finalidade de fornecer a descrição geral de uma sessão utilizam-se variáveis agudas tais como escolha dos exercícios, velocidade de execução, sobrecarga de treinamento, intervalo de recuperação, dentre outras (Fleck \& Kraemer, 2006).

A sobrecarga ou carga é, definitivamente, um fator-chave dentro de qualquer programa de treinamento resistido, pois, além de determinar um nível de intensidade, ela é o principal estímulo relacionado às alterações observadas nas mensurações de força e resistência muscular localizada (Tan, 1999; Fleck \& Kraemer, 2006). A variação da intensidade do treinamento pode estar relacionada com as diferentes ações musculares. Sabe-se que existem três tipos de ações musculares; concêntricas, excêntricas e isométricas. A primeira consiste no encurtamento do músculo, ou seja, a contração propriamente dita. A segunda consiste no alongamento das fibras de maneira controlada, refere-se ao retorno à posição inicial do exercício em questão. E finalmente a última consiste na ativação muscular sem movimentação da articulação que está sendo solicitada, respectivamente (Fleck \& Kraemer, 2006; McArdle, 2008). Atualmente, existe ainda o movimento do tipo isocinético que, durante a ação concêntrica e excêntrica, possui velocidade constante (Azevedo, 2003; Bottaro et al., 2005). Esse tipo de controle de velocidade tem se mostrado uma boa opção para o 
treinamento muscular e reabilitação articular, pois o executante deve atingir o grau de força desejado e executá-lo durante todo o movimento a partir da velocidade solicitada (Farina et al., 1999; Azevedo, 2003).

Ao analisar as contrações dinâmicas (ações concêntrica e excêntrica) existem tecnologias que podem influenciar diretamente o controle da variável de intensidade. Exercícios praticados em polias, pesos livres ou maquinário caracterizam-se por exercer uma carga constante. Apesar das variações nos ângulos de vantagem e desvantagem mecânica a sobrecarga é a mesma do início ao final do movimento. Exercícios praticados com resistência elástica possuem uma variação de carga ao longo da amplitude de movimento. Essa variação tenta acompanhar os aumentos e reduções de força durante a amplitude de movimento pelo aumento ou diminuição da deformação elástica (Fleck \& Kraemer, 2006; Martins et al., 2013). Segundo Sakanoue et al. (2007), a variação da resistência acompanha a curva de força do exercício onde o músculo ativo é forçado a contrair de forma crescente ao longo da amplitude de movimento.

O treinamento resistido através de cargas constantes é bem descrito na literatura por possibilitar o controle de intensidade. Estudos que propõe diferentes protocolos de exercícios conseguem descrever os aumentos de sobrecarga no decorrer das semanas de treinamento e explorar variáveis fisiológicas e mecânicas que influenciam os ganhos de força e/ou volume muscular (Schoenfeld, 2010). Prestes et al. (2009) verificaram o efeito de um programa de treinamento de 12 semanas com diferentes modelos de periodização nos níveis de força e composição corporal de indivíduos praticantes de treinamento resistido. Seu estudo explicita a importância em se ter o controle da intensidade no treinamento resistido de cargas constantes onde todas as sobrecargas usadas para se executar o protocolo experimental embasaramse em percentis determinados a partir do teste de 1RM, no qual determina a sobrecarga máxima para executar um determinado movimento com a técnica correta (Rocha Júnior, 2008). Isso possibilitou a quantificação de carga a ser utilizada em cada exercício além do acompanhamento semanal para ajustar intensidade e volume até completarem as 12 sessões.

A polia, especificamente, pode ter uma configuração de raio variável que a "transforma" em um método resistivo de comportamento variável, assim como o 
elástico (figura 1). Essa variação em seu raio possui o intuito de permitir que o torque gerado pelo exercício tenha comportamento crescente (McMaster et al., 2009). Fleck e Kraemer (2004) descreveram que para o exercício de flexão do cotovelo em polias de raio variado a resistência oferecida no meio da amplitude do movimento é maior comparado à primeira porção e no último quarto movimento.

Figura 1 - Variação do raio de um maquinário para o exercício "pullover" (McMaster et al., 2009).
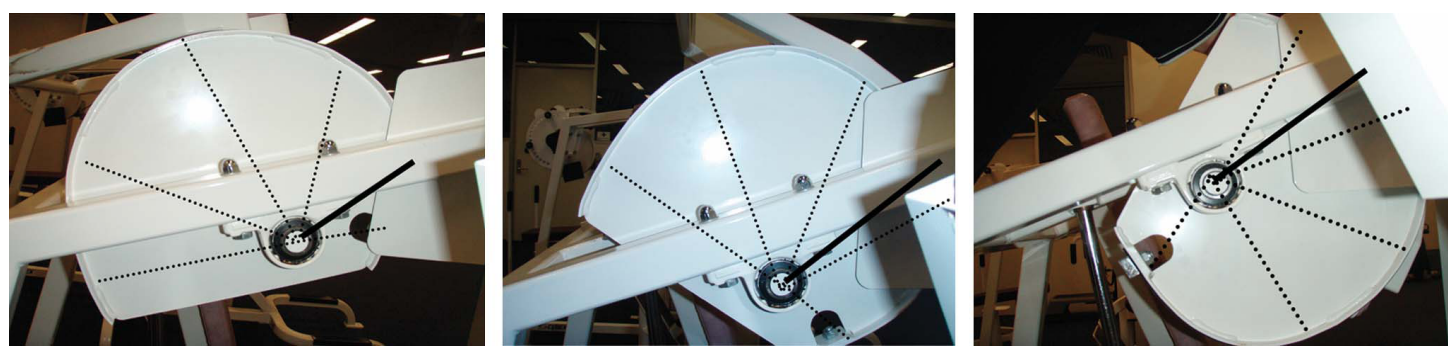

Em destaque, o raio de tamanho variado em negrito durante o movimento do equipamento

Quando associados à eletromiografia de superfície, muitos estudos enfocam nas variações de movimento e nos diferentes maquinários, buscando entender os mecanismos que ajudam a musculatura ativa a atingir determinados níveis de força. Como exemplo, o estudo de Schwanbeck et al. (2009) comparou a ativação muscular dos motores primários do movimento de agachamento, assim como seus estabilizadores, com uso de pesos livres e no maquinário Smith. Como resultado, obteve um aumento significativo na ativação dos músculos gastrocnêmios, bíceps femoral e vasto medial na execução com pesos livres quando comparado ao maquinário. Com o mesmo desenho experimental Welsch et al. (2005) analisaram a atividade eletromiográfica dos músculos peitoral maior clavicular e deltóide anterior no movimento de supino com halter, com barra e movimento "crucifixo" com halter. Diferenças na ativação das unidades motoras não foi estatisticamente significante para nenhum dos três movimentos. No entanto observa-se uma lacuna nos estudos que comparam resistência fixa comparada à variável.

Considerada exemplo de carga variável, a resistência elástica possui características singulares. Ao contrário da polia em que a força exercida oferece uma menor resistência ao final do movimento de flexão do cotovelo (Fleck \& Kraemer, 2006), na resistência elástica, a intensidade imposta, associada ao tipo de material e 
aos níveis de deformação alcançados, torna-se maior ao final da amplitude de movimento (Simoneau et al., 2001). Em um ensaio mecânico realizado por Martins et al. (2014) foi verificado que elásticos comerciais em forma de tubos, comumente utilizados para a prática de exercícios físicos, impõem um aumento de carga diretamente proporcional ao estiramento do material. Essa quantificação de carga torna o uso do implemento elástico mais objetivo, facilitando o controle da intensidade. Porém, o comportamento da deformação elástica analisada pelos autores é muito específica a um único tipo de elástico e marca. A reprodutibilidade desses valores para outros tipos de implemento não foi realizada, mantendo assim a problemática de ausência de controle quantitativo de carga para elásticos.

Dentro desse contexto, o controle de carga para resistências variáveis torna-se subjetivo e a comparação com resistências fixas um desafio. Segundo Andersen et al. (2010) poucos estudos analisaram adaptações fisiológicas induzidas por exercícios com resistências elásticas comparados a outras modalidades de contração. Além disso, estudos anteriores verificaram que o uso de resistência elástica em intensidade adequada proporcionam melhoras significativas em testes funcionais e provocam mudanças na composição corporal com diminuição da perimetria abdominal e percentual de gordura corporal (Colado et al. 2008, 2009) em diferentes populações. Jakobsen et al. (2014) compararam a efetividade da reabilitação de flexores de joelho em exercícios feitos com resistência elástica e maquinário de musculação através da eletromiografia de superfície. Em seus resultados, houve similaridade na ativação muscular para ambas as tarefas apesar da tarefa com sobrecarga elástica apresentar valores maiores na percepção de esforço quando comparada ao maquinário. Os autores justificaram esse resultado pelos vários graus de liberdade da perna quando executado o movimento de flexão de joelhos. Quanto aos ganhos de força, Calatayud et al. (2015) encontraram, através do nível de ativação muscular e testes de 1RM e 6RM, ganhos similares para o exercício de supino reto realizado com barras e anilhas comparado ao movimento de flexão de braços realizado com resistência elástica.

No entanto, a falta de consistência de estudos na literatura que propõem métodos e protocolos capazes de quantificar a intensidade de exercícios com carga variável dificulta a padronização de testes de força assim como os já realizados com resistência constante. Tal fato prejudica a investigação das respostas fisiológicas e 
interações biomecânicas oriundas dos diferentes métodos de sobrecarga (Azevedo, 2003; Martins, 2013).

$\mathrm{Na}$ tentativa de controlar a intensidade de forma mais objetiva, autores como Fuller (1997), Hunter et al. (2001), Oliveira et al. (2009) e Melchiorri et. al. (2011) propõem o uso de biofeedback no controle de variáveis agudas do TR. Essa técnica advém do fenômeno "feedback" que é entendido como um conjunto de mecanismos de controle capazes de se adaptarem a situações rotineiras ou até mesmo fisiológicas (Fuller, 1977). São várias as formas de fornecer feedback a um praticante de exercício físico. Moras et al. (2009), utilizaram um metrônomo para controle da velocidade de execução do exercício supino com diferentes intensidades. Essas intensidades foram determinadas através do uso do teste de 1RM para resistência fixa.

Segundo Rosa de Sá et al. (2012), o biofeedback surge como um elemento de apoio que permite ao praticante, de forma voluntária ou indireta, aprender a controlar parâmetros fisiológicos do organismo. Para tanto, necessita-se de algum meio que forneça ao indivíduo informações biológicas (tensão muscular, temperatura da pele, atividade cerebral, frequência cardíaca) e/ou psicofisiológicas (grau de estresse, relaxamento, excitação, ansiedade) que o mesmo não poderia inferir diretamente. Esta técnica pode ser constituída desde um simples espelho a um sofisticado aparelho eletrônico. O importante é que sejam fornecidos subsídios imediatos para pessoa saber o que ocorre em seu corpo em um determinado momento (Rosa de Sá et al., 2012).

O estudo de Melchiorri et al. (2011) descreve o uso de biofeedback para comparação da curva de força de métodos resistivos diferentes. Para indicar a faixa de intensidade em que o sujeito deveria executar o protocolo, transdutores de força foram conectados a um display que provia ao indivíduo um biofeedback visual sobre o nível de torque produzido. Ainda Hunter et al. (2001) utilizaram a ferramenta de biofeedback visual com a finalidade de fornecer informações sobre a correta angulação da articulação do cotovelo em uma das tarefas executada em seu protocolo experimental.

Além disso, escalas de percepção de esforço (PSE) também podem ser usadas como biofeedback para avaliar o nível de intensidade durante o exercício (Robertson 
et al., 2003; McArdle, 2008). O estudo de Oliveira et al. (2009) comparou o sinal de SEMG e a frequência cardíaca com os resultados obtidos pelo uso de uma escala de percepção subjetiva de esforço no movimento de flexão do cotovelo em diferentes posições (em pé e sentado). Os resultados encontrados por esses autores corroboram com a utilização dessa técnica para avaliar níveis de intensidade. Martins (2013), utilizou PSE para controlar a intensidade de um programa de treinamento de força muscular com uso de resistência elástica em idosos. Tal procedimento exemplificou o atual contexto da utilização da resistência elástica onde o controle de carga durante o exercício é inexistente ou feito através de uma escala subjetiva de esforço para resistência elástica (OMNI-RES) validada por Colado et al. 2012 e representada na figura 2.

Figura 2 - OMNI resistance exercise scale of perceived exertion para uso com bandas elásticas (Colado et al. 2012).

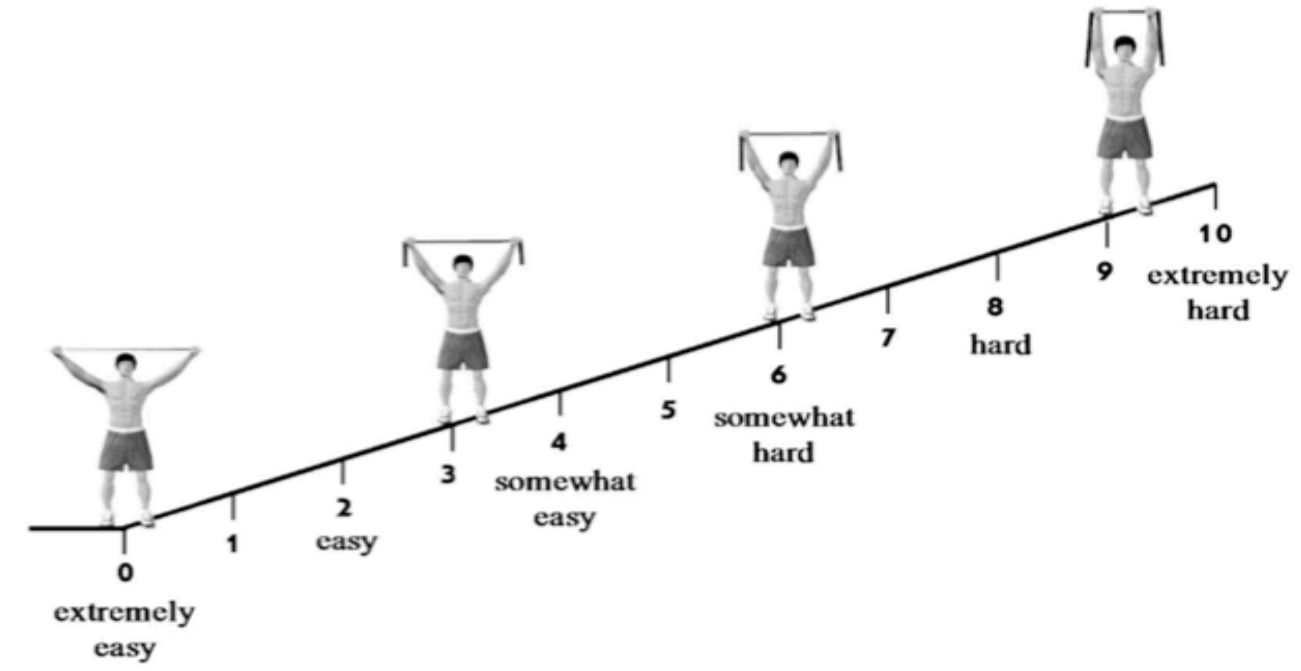

\subsection{Eletromiografia}

A eletromiografia (EMG) é uma técnica que consiste na aquisição e tratamento do sinal elétrico produzido na musculatura a partir da estimulação de unidades motoras em função do tempo (Merletti e Parker, 2004). Essa técnica possibilita inferências acerca das propriedades fisiológicas como a fadiga muscular além dos mecanismos de produção de força (Anders et al., 2005). Além disso, a eletromiografia 
possui dois métodos de aquisição. Um de caráter invasivo, onde os eletrodos são inseridos diretamente na musculatura e possuem formatos de agulha, ou de caráter não invasivo, onde os eletrodos são posicionados na superfície da pele (De Luca, 1997). Essa técnica pode ser afetada por diversos fatores como propriedades musculares, anatômicas e fisiológicas, pelo controle do sistema nervoso periférico e a instrumentação utilizada (Mezzarane et al., 2014).

Tratando-se da eletromiografia de superfície (SEMG), o tipo de eletrodo, seu formato e composição influenciam diretamente na captação e qualidade do sinal (De Luca, 1997; Merletti e Parker, 2004; Andrade, 2006; Rocha Júnior, 2008; Pereira, 2009). Como forma de aperfeiçoar a captação e minimizar os ruídos, são utilizados eletrodos de tamanho razoável para manter-se no ventre do músculo analisado e que permitam um bom contato com a pele (De Luca, 1997). Sua composição é frequentemente de prata clorada $(\mathrm{Ag}-\mathrm{AgCl})$ a qual oferece uma baixa impedância com a pele e seu funcionamento está ligado a um sistema de amplificação diferencial (Hermens et al., 2000). A configuração bipolar de eletrodos tem sido comumente utilizada e capta sinais eletromiográficos distintos por meio de dois contatos. Durante a aquisição, um eletrodo adicional é colocado em uma região óssea ou tendínea próxima ao evento estudado com a finalidade de ser utilizado como referência de sinal comum a todos os eletrodos. As diferenças dos sinais obtidos são então amplificadas, sendo esse método chamado de amplificação diferencial simples, como ilustrado na figura 3. O sinal comum, resultante das diferenças entre os sinais obtidos, é então rejeitado (ruído). A capacidade de rejeitar o sinal comum é chamada de taxa de rejeição de modo comum. 
Figura 3 - Representação da amplificação diferencial de um eletrodo bipolar.

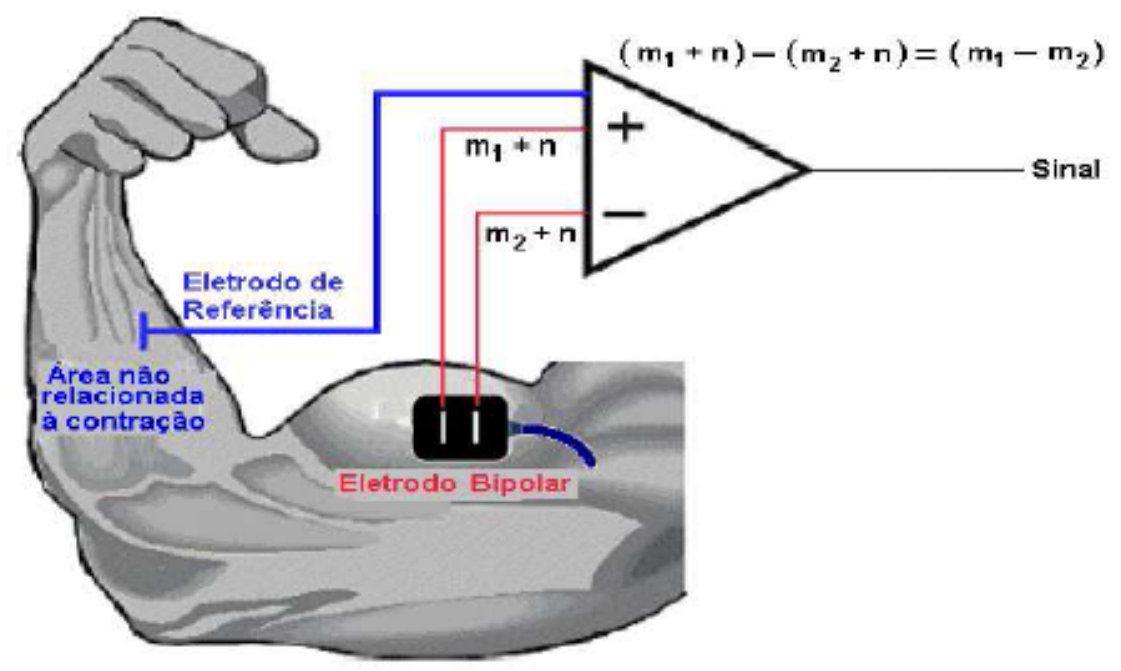

Os sinais eletromiográficos obtidos são representados por "m1" e "m2", e o ruído por "n" (modificado - De Luca, 2002; Rocha Júnior, 2006)

Os eletrodos podem receber ainda a classificação de ativos ou passivos. Eletrodos ativos são aqueles que possuem um circuito eletrônico responsável por fazer uma amplificação prévia dos sinais captados antes de chegarem ao eletromiógrafo (instrumento responsável pelo tratamento do sinal eletromiográfico) (Marchetti et al., 2006). A amplificação prévia pode ser acompanhada de uma filtragem do sinal e a eliminação de ruídos de baixas e altas frequências, ou seja, ruídos relacionados a artefatos de movimento ou de outras naturezas. Eletrodos passivos são aqueles que apenas captam o sinal eletromiográfico, sem nenhum tratamento prévio até a chegada do mesmo ao eletromiógrafo (Marchetti et al., 2006).

O SENIAM (Surface EMG for the Non-Invasive Assessment of Muscles) possui recomendações para utilização e colocação de eletrodos de superfície como forma de padronizar a utilização dos mesmos e evitar grandes interferências prejudiciais com a localização de pontos motores. Sabe-se que a qualidade do sinal pode ser comprometida pela captação do sinal elétrico cardíaco, crosstalk (sinal elétrico oriundo de músculos próximos ao músculo estudado), artefatos de movimento e direção do eletrodo em relação às fibras musculares (De Luca, 1997). A figura 4 representa as mudanças na amplitude e frequência do sinal eletromiográfico captado por um eletrodo de configuração bipolar em diferentes regiões do músculo. 
Figura 4 - Alteração do sinal da amplitude e espectro de frequência do SEMG com a variação da colocação do eletrodo (modificado - De Luca, 1997).
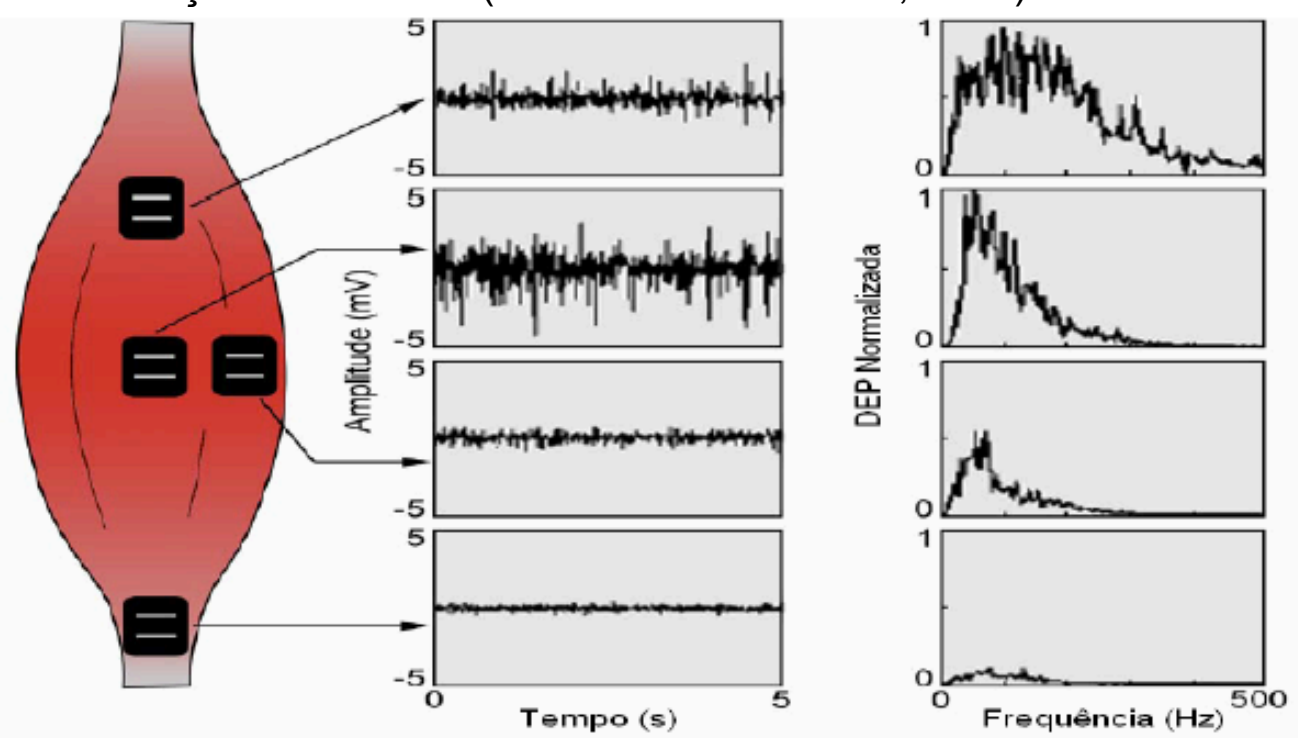

DEP é a densidade espectral de potência (modificado - Andrade, 2006).

Embora as recomendações advindas do SENIAM sobre o posicionamento do eletrodo na pele, dos procedimentos prévios e da construção dos sensores sejam uma tentativa de minimizar os ruídos, sabe-se que aquisições livres dos mesmos são impossíveis (Konrad, 2005). Dessa forma, pesquisadores e clínicos devem ter o conhecimento sobre as principais fontes de ruído e buscar soluções para minimizar sua ocorrência.

Tratando-se de contrações dinâmicas, sabe-se que há uma movimentação do eletrodo sobre a pele além da movimentação muscular. Esses fatores podem gerar artefatos de movimento que possuem frequências variando entre 0 e $20 \mathrm{~Hz}$ (Merletti e Parker, 2004). Esse tipo de ruído pode ser minimizado pela correta fixação do eletrodo na pele e dos cabos conectados ao mesmo. Como forma de diminuir a impedância da pele, procedimentos de abrasão e tricotomia são adotados para melhorar a captação do sinal dentro de circunstâncias dinâmicas e isométricas (Webster, 1984).

Campos eletromagnéticos são fontes comuns de ruído durante a aquisição de sinais eletromiográficos de superfície. No Brasil, esse ruído advém, com frequência, da corrente alternada fornecida pelas operadoras de energia elétrica, com valor de $60 \mathrm{~Hz}$, e/ou suas harmônicas. Normalmente, a amplitude desse sinal é superior à 
amplitude do sinal eletromiográfico (Andrade, 2006; Rocha Júnior, 2008; Pereira, 2009). Como forma de amenizar sua captação, Clancy et al. (2002) propuseram diferentes estratégias de atenuação de ruídos de diversas naturezas. Sugestões como utilizar amplificadores diferenciais e acessórios blindados além de mantê-los entrelaçados, diminuem sua exposição a diferentes faixas de campos eletromagnéticos. Além disso, garantir um bom aterramento (ambiente e paciente) e utilizar nobreaks durante a aquisição corroboram na tentativa de diminuir a captação de ruídos.

A aquisição de sinais eletromiográficos de superfície envolve hardwares adequados para realizar o sistema de amplificação diferencial e rejeição de modo comum. O sinal analógico emitido pelo corpo deve ser convertido para um sinal digital através de um conversor análogo-digital e possibilitar seu registro no computador. Tal configuração necessita de ajustes como frequência de amostragem, amplificadores, filtros, conversor análogo-digital, dentre outros (De Luca, 2002; Marchetti et al., 2006).

A conversão de um sinal analógico em digital necessita de parâmetros que possibilitem a reprodução correta para que possam ser feitas inferências adequadas. A frequência de amostragem consiste na leitura do sinal em instantes específicos associados ao período de amostragem (De Luca, 2003). Caso o sinal seja reproduzido digitalmente com uma baixa frequência, este pode não conter todas as informações relevantes (Erfanian et al. 1994, ; De Luca, 2003). A frequência de amostragem segue o teorema proposto por Nyquist o qual define que a reconstrução do sinal digital deve usar no mínimo o dobro de sua maior frequência. No caso da eletromiografia, sendo a frequência máxima de $500 \mathrm{~Hz}$, a frequência de amostragem deve ser no mínimo de $1000 \mathrm{~Hz}$ (De Luca, 2003). Tratando-se de amplificadores diferenciais e taxa de rejeição de modo comum, recomenda-se, pelo menos, um valor de 100dB para garantir e melhorar a qualidade do sinal (Clancy et al., 2002; De Luca, 2003).

Os filtros são ferramentas utilizadas para atenuar variações específicas de componentes frequenciais, ou seja, permitindo a separação e restauração do sinal desejado (Carmo, 2003; Rocha Júnior, 2008). A separação faz-se necessária quando o sinal foi contaminado por alguma interferência ou ruído. Já a restauração é utilizada quando há alguma distorção do sinal (Marchetti et al., 2006). Aplicações do sinal 
eletromiográfico em frequências acima de $500 \mathrm{~Hz}$ não correspondem a fatores fisiológicos, que no caso, seria a contração muscular (Merletti e Parker, 2004). Dessa forma, os filtros passa-banda com frequências de corte entre 20 e $500 \mathrm{~Hz}$ são utilizados para análises do sinal (De Luca, 1997; Merletti e Parker, 2004). Os filtros podem ser analógicos ou digitais (De Luca, 2003).

Os métodos clássicos de análise do sinal de EMG resumem-se em análise no domínio do tempo e no domínio da frequência. A informação representada no domínio temporal descreve quando algo ocorre e qual a amplitude de sua ocorrência (Carmo, 2003; Pereira, 2009). Tal parâmetro pode indicar a magnitude da atividade muscular pelo nível de ativação das unidades motoras recrutadas e pela taxa de disparo das unidades motoras ativas (Farina, 2004). Os métodos mais comuns de interpretação do sinal de EMG no domínio do tempo são o RMS e o ARV (De Luca, 2002; Merletti e Parker, 2004). A amplificação do sinal eletromiográfico de superfície se faz necessária tendo em vista a variação de amplitude de apenas 0 a $10 \mathrm{mV}$ pico a pico (De Luca, 2002) podendo a análise dos sinais brutos provocar inferências equivocadas. Dependendo do tipo de método escolhido, procedimentos prévios como a retificação e normalização do sinal são essenciais.

A retificação completa consiste em eliminar os valores negativos do sinal ao converte-los em valores positivos, conservando assim a energia do sinal eletromiográfico de superfície (De Luca, 2006). Esse método faz-se necessário pois a amplitude do sinal bruto varia entre valores positivos e negativos já que correspondem ao fenômeno de polarização e despolarização da membrana muscular e devido à medição diferencial. Caso a retificação do sinal não seja feita, cálculos de amplitude do mesmo podem ser subestimados e irreais. 
Figura 5 - Sinal eletromiográfico bruto e retificado por onda completa (Marchetti et al., 2006)
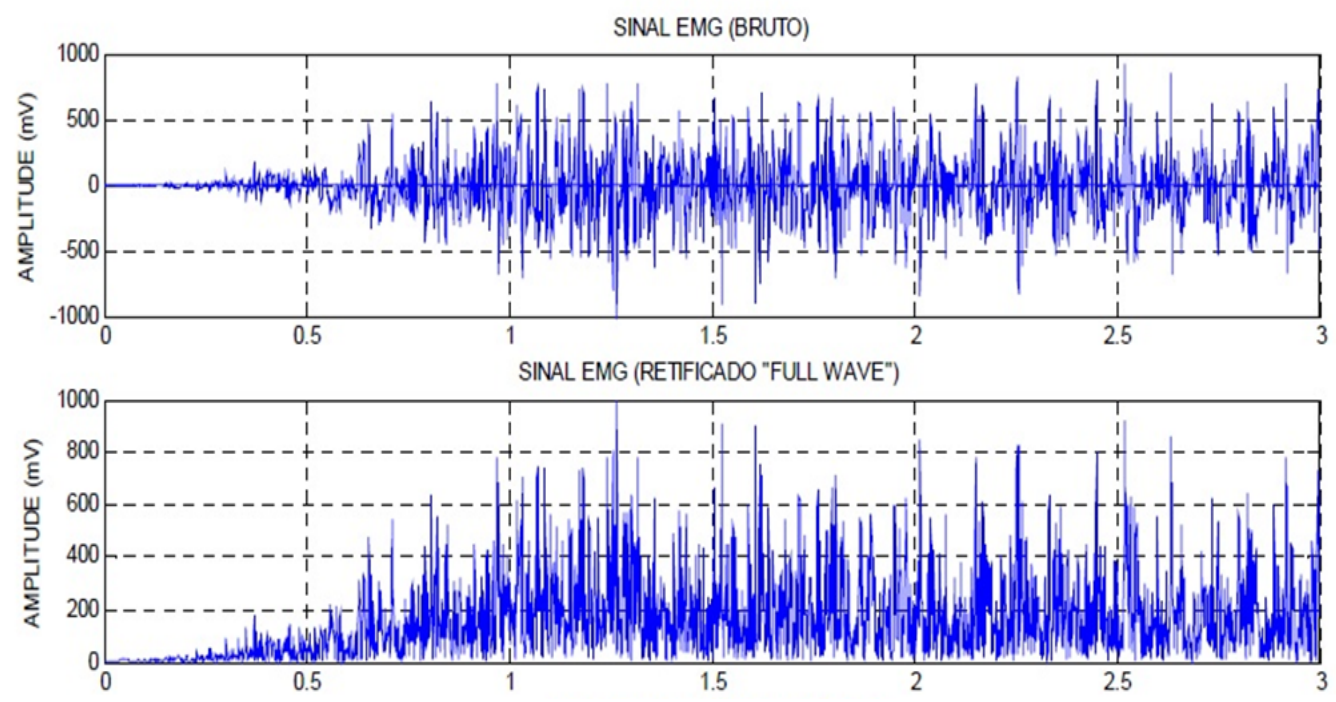

Após a retificação do sinal (figura 5), o procedimento de normalização consiste em reestabelecer o fundo de escala do sinal eletromiográfico a partir de uma determinada referência. Tal procedimento possibilita comparações entre os sinais de diferentes sujeitos e/ou grupos (Marchetti et al., 2006) e pode ser feito de três principais maneiras diferentes. A primeira delas tem como referência a contração voluntária isométrica máxima (CVIM), onde o sinal dessa contração é definido como $100 \%$ da atividade elétrica muscular e os demais valores da escala são convertidos em percentuais relativos a esse máximo (De Luca, 1997). Outras formas de normalização são baseadas no valor médio ou no valor máximo do próprio sinal.

Após a retificação e normalização do sinal, respectivamente, o cálculo do nível de ativação muscular é feito pelo método da raiz do valor médio quadrático (Root Mean Square - RMS) ou pela amplitude média do sinal retificado (Average Rectified Value - ARV). Para calcular o valor RMS realiza-se a soma de todas as amostras do sinal da SEMG elevadas à segunda potência. Esse somatório é dividido pelo número total de amostras e extrai-se a raiz quadrada do quociente obtido (De Luca, 1997). Já o ARV consiste no somatório do sinal retificado em um intervalo de tempo, dividido pelo tamanho do intervalo (Merletti et al., 1999). As equações 1 e 2 mostram como encontrar essas estimações de amplitude do sinal de SEMG para $m$-ésima janela do sinal. 


$$
\begin{aligned}
& \operatorname{RMS}(m)=\sqrt{\frac{1}{N}} \sum_{n=0}^{m N-1}\left|f(n)^{2}\right| \\
& \operatorname{ARV}(m)=\frac{1}{N} \sum_{n=0}^{m N-1}|f(n)|
\end{aligned}
$$

Apesar dessas ferramentas matemáticas serem similares e permitirem inferências sobre o nível de ativação muscular (Merletti et al., 1999, De Luca 2002, Konrad, 2005) e/ou associações entre a amplitude do sinal e valências físicas, o valor RMS é consagrado na literatura e consistente em demonstrar linearidade tanto para contrações dinâmicas quanto isométricas quanto a amplitude do sinal eletromiográfico (Moritani et al., 1987; De Luca, 1997; Alkner et al., Masuda et al., 2001; Bilodeau et al., 2003).

No domínio da frequência tem-se uma representação do SEMG em um espectro de frequências, onde o conteúdo do sinal é representado como um histograma e normalmente utilizando a Transformada Rápida de Fourier (Moritani et al., 1987; Christensen et al., 1995; Andrade, 2006). Fisiologicamente, existem alguns parâmetros que podem influenciar a representação desse sinal no domínio da frequência como a taxa de disparo das unidades motoras, o tempo relativo de disparo dos potenciais de ação por diferentes unidades motoras e a forma dos potenciais de ação (Carmo, 2003; Pereira, 2009; Rocha Júnior, 2008; Soares, 2013). Tais alterações podem ser inferidas na presença da fadiga muscular localizada, a qual se origina em uma região muscular definida, submetida a uma atividade física intensa por um determinado tempo (Chaffin, 1973).

A identificação de padrões associados a fadiga muscular localizada em contrações isométricas e dinâmicas com o uso da SEMG correspondem a uma importante área de investigação do sistema motor. Nesse sentido, inúmeras técnicas e protocolos são estabelecidos na tentativa de entender ou até mesmo padronizar um comportamento ou adaptação ao treinamento (Carmo, 2003). Gelerman et al. (1996) e Lindstrom et al. (1970) mostraram que a presença da fadiga muscular localizada atribui uma assinatura espectral ao sinal de SEMG com a presença de um declínio 
dos potenciais de ação em amplitude e aumento de sua duração, deslocando o gráfico de espectro de frequência para a esquerda.

Os estimadores de frequência mais comumente utilizados para o sinal de SEMG são a frequência de potência média (FPM) e frequência de potência mediana (FPMd). Normalmente, utiliza-se o estimador de FPMd por ser menos sensível à ruído e mais sensível à fadiga, o que é desejado em vários estudos (Soares, 2013). O estimador FPMd é calculado para $m$-ésima janela do sinal de SEMG encontrando o menor valor de $k_{m}$ tal que

$$
\sum_{k=0}^{K m}|F m(k)|^{2} \geq \frac{1}{2} \sum_{k=0}^{N / 2}|F m(k)|^{2}
$$

e então calculando $\operatorname{FPMd}(m)=f s(K m / N)$, onde $f s$ é a frequência de amostragem (em $\mathrm{Hz}$ ), $F m(k)$ é a transformada discreta de Fourier da $m$-ésima janela do sinal e $N$ é o número de amostras na janela (Soares, 2013).

Ainda, Christensen et al. (1995) afirmaram que os valores de RMS e FPMd são crescentes e decrescentes, respectivamente, para contrações isométricas. Fisiologicamente, essa assinatura espectral pode ser justificada pelo recrutamento adicional das unidades motoras e/ou maior sincronização e diminuição da taxa de disparo, mudanças na sincronização e diminuição da velocidade de condução (Andrade, 2006). No caso de contrações dinâmicas, Merletti e Parker (2004) e Bonato et al. (1996) associam a dificuldade em não encontrar padrões espectrais para os parâmetros fadiga muscular pela não estacionariedade do sinal mioelétrico dadas pelas alterações no comprimento muscular além dos artefatos de movimento. 


\section{CAPÍTULO 3 - MATERIAIS E MÉTODOS}

\subsection{Amostra}

A amostragem por conveniência foi composta por 31 indivíduos saudáveis do sexo masculino (idade: 29,03 $\pm 5,99$ anos, massa: $81,81 \pm 8,65 \mathrm{~kg}$, estatura: 179,09 \pm $5,05 \mathrm{~cm}$ ). Os voluntários possuíam experiência de no mínimo seis meses em treinamento resistido e consentiram participar do estudo após assinar um termo de consentimento no qual explicitava todos os procedimentos metodológicos, riscos e benefícios além de alertá-los sobre a desistência e abandono da participação por livre e espontânea vontade (TCLE - Anexo I). Foram usadas como critério de exclusão a presença de doenças crônicas ou lesões relacionadas ao sistema musculoesquelético ou qualquer outra patologia que pudesse prejudicar a participação no estudo. $O$ projeto foi aprovado junto ao Comitê de Ética em Pesquisa (CEP) da Faculdade de Ciências da Saúde (CAAE: 16303013.0.0000.0030).

\subsection{Introdução aos Protocolos Experimentais}

O treinamento resistido possui diversas variáveis que interferem de forma aguda e/ou crônica no desenvolvimento das capacidades físicas. A carga do exercício é um exemplo de variável na qual o executante deve cumprir durante a execução de uma tarefa (Fleck \& Kraemer, 2006). Desta forma, o controle da carga permite ao praticante não só um acompanhamento evolutivo de seu treinamento, mas também ações imediatas no padrão de movimento e técnica de execução para cumprimento da tarefa em parâmetros de intensidade e volume de treino (Tan, 1999).

Quando o treinamento é realizado com pesos livres, polias ou máquinas, temse a carga constante, mas o torque é variável. As mudanças de intensidade variam 
pelas alavancas dos membros corpóreos, ou seja, apesar da carga ser a mesma do início ao final do movimento, existem variações angulares que geram maiores ou menores desvantagens mecânicas (Hall, 2000). Contudo, o treinamento no qual utiliza resistências elásticas, esse princípio é modificado pela variação de carga. No caso do elástico, a medida que a deformação causada é maior, ocorre um aumento progressivo da carga (Martins et al., 2014).

Com o intuito de comparar e normalizar intensidade usada em exercícios com carga fixa e variável (elástico), os protocolos aplicados no estudo procuraram reproduzir duas tarefas similares em termos de sobrecarga. A tarefa realizada na polia representa o exercício sendo realizado com carga constante e foi usada como padrão de comparação com as tarefas realizadas com resistência elástica. Assim, todos os indivíduos, sejam do GBIO ou GTRD, a realizaram. A tarefa polia também foi usada para familiarização com a carga de teste.

As tarefas com resistência elástica foram executadas de duas formas diferentes. No grupo com biofeedback (GBIO), as tarefas foram realizadas com o uso do biofeedback sonoro e visual, garantindo ao executante que o mesmo encontrava-se dentro da faixa de carga variável solicitada. No grupo tradicional (GTRD), as tarefas com resistência elástica dependeram da percepção subjetiva de esforço do próprio executante, método este mais comumente utilizado atualmente.

\subsection{Descrição dos Protocolos Experimentais}

A fim de responder questões sobre o padrão de recrutamento muscular e fadiga durante exercícios feitos com diferentes tipos de resistência e ainda possibilitar um controle de carga quantitativo para implementos elásticos por meio de biofeedback, o presente estudo idealizou uma metodologia na qual possibilita fazer inferências sobre as variáveis eletromiográficas e responder estatisticamente ao objetivo proposto em relação à quantificação e controle de carga para resistência elástica.

Todos os protocolos foram realizados no Laboratório de Processamento de Sinais Biológicos e Controle Motor da Faculdade de Educação Física da Universidade 
de Brasília (FEF/UnB). Os protocolos consistiram em executar doze (12) repetições do movimento de flexão de cotovelo à $30 \%$ da CVIM em uma polia baixa (Gervasport fitness equipment囚) ou com implementos elásticos (Elastos $®)$.

Os voluntários foram alocados em dois grupos de forma contrabalanceada: grupo com controle objetivo de carga e biofeedback (GBIO, n=16) ou grupo com controle subjetivo de carga (GTRD, $n=15$ ).

Todos os voluntários realizaram três tarefas distintas. A primeira, utilizada como padrão de comparação, foi realizada na polia com $30 \%$ da carga da CVIM. Essa tarefa era obrigatoriamente a primeira com o intuito de familiarizar o sujeito com a carga a ser usada também na tarefa com resistência elástica. As demais tarefas com resistência elástica foram realizadas com $30 \%$ da carga da CVIM ao iniciar o movimento (ângulo do cotovelo em extensão máxima) denominada de $\mathrm{BIOi}$, onde o "i" indica início e a outra tarefa com $30 \%$ da carga da CVIM no meio do movimento (ângulo do cotovelo a aproximadamente 90 graus) denominada de $\mathrm{BIOm}$, onde o " $m$ " indica meio. A ordem das tarefas com resistência elástica foi feita de forma contrabalanceada e um intervalo de 10 minutos foi dado entre a execução das mesmas (Melchiorri et al., 2001).

O dispositivo de controle de resistência variável com biofeedback usado no presente estudo para o grupo GBIO funciona de acordo com uma faixa, em quilogramas, previamente programada para ser atingida. No caso do protocolo experimental, assim que os $30 \%$ da CVIM eram atingidos, o dispositivo emitia um feedback visual por meio de um led de cor verde e um feedback sonoro advertindo que o sujeito havia atingido a carga proposta. Caso o sujeito não alcançasse o limite programado, o led mudava sua cor para o vermelho e um bip contínuo era acionado simultaneamente.

Os participantes do GTRD realizaram as mesmas três tarefas do GBIO iniciando pela polia (figura 6). No entanto, para controle da intensidade durante as tarefas com elástico, o sujeito posicionava-se de acordo com sua percepção de esforço a fim de atingir a carga proposta para as tarefas executadas. Para o grupo tradicional, denominou-se TRDi a tarefa onde o voluntários acreditavam ter atingido os $30 \%$ da CVIM no inicio da execução do movimento e TRDm ao ser atingida esta 
mesma carga durante o meio do movimento. O protocolo experimental está resumido na figura 7 .

Figura 6 - Tarefas na polia (TRDp) e com resistência elástica (TRDi) do Grupo Tradicional (GTRD), respectivamente.

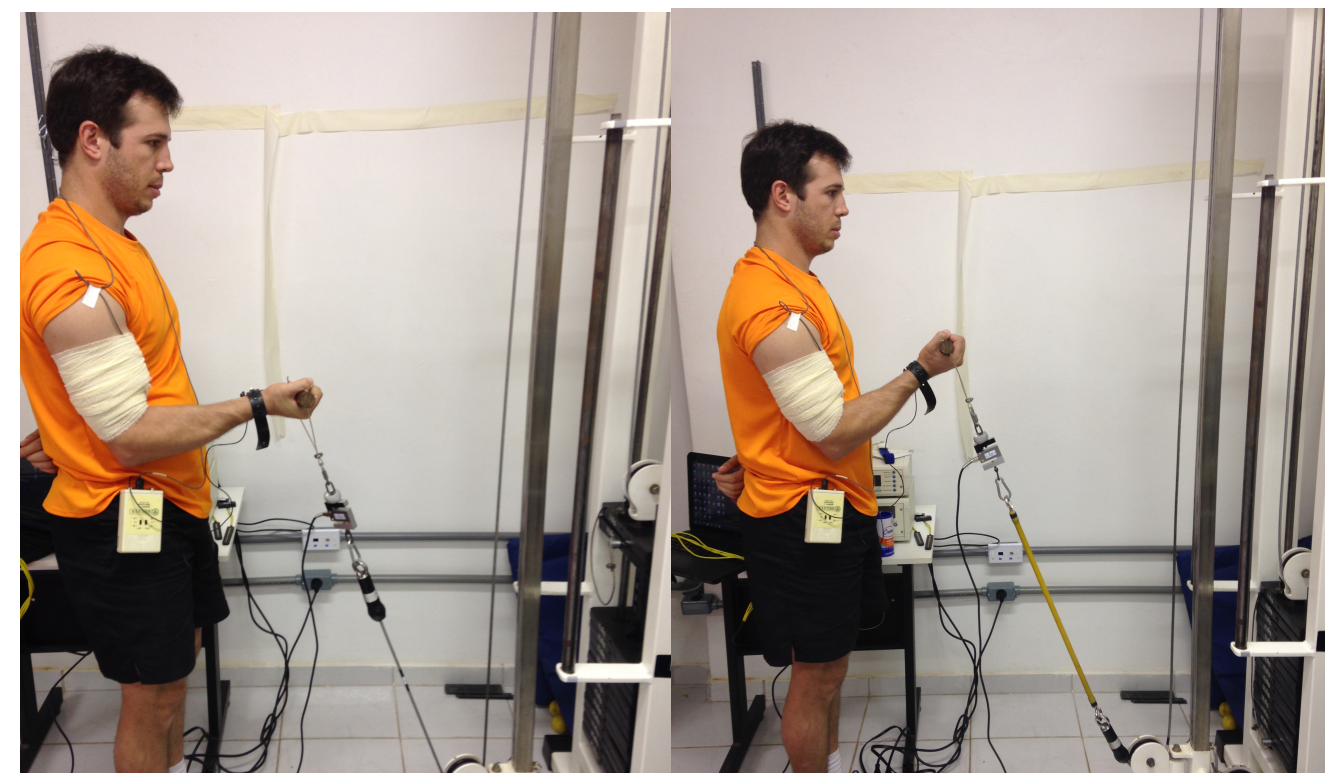

Figura 7 - Diagrama dos Protocolos Experimentais da pesquisa.

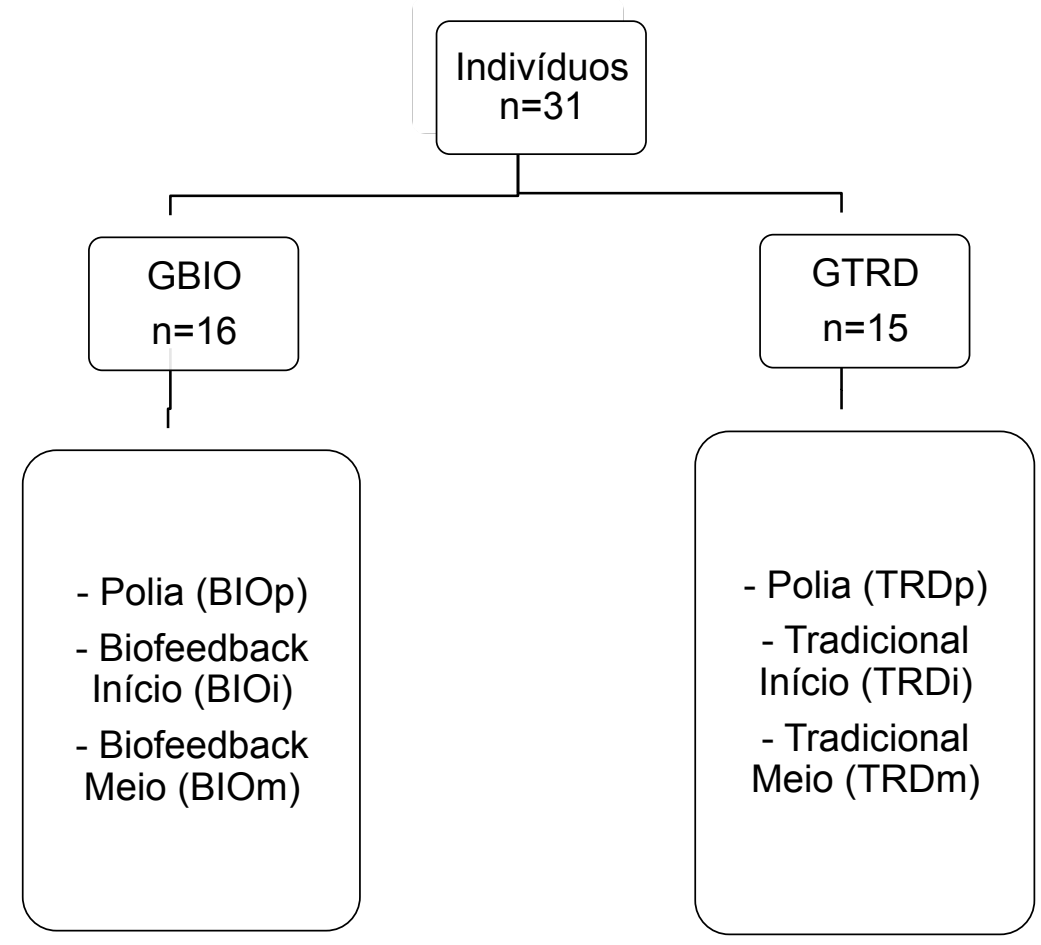


As repetições da flexão do cotovelo foram realizadas com o braço dominante em ritmo pré-estabelecido por um metrônomo de dois segundos para a fase concêntrica e dois segundos para a fase excêntrica (2020) (Melchiorri et al., 2001).

\subsection{Procedimentos}

Após a chegada ao laboratório, todos os procedimentos foram explicados ao voluntário e o mesmo assinou o TCLE antes do inicio das coletas. Feito isso, foram realizadas medidas antropométricas para caracterização da amostra. Após a alocação do voluntário em um dos grupos experimentais o mesmo foi submetido a um teste para avaliar a CVIM dos flexores de cotovelo e determinar a carga a ser utilizada para as tarefas.

\subsubsection{Célula de Carga e Eletrogoniômetro}

Para aquisição dos sinais de força, uma célula de carga (AEPH do Brasil Indústria e Comércio Ltda., modelo TS, $50 \mathrm{~kg} \pm 10 \%$ ) foi utilizada durante a CVIM durante as tarefas com resistência fixa para ambos os grupos e resistência elástica apenas para o grupo GTRD. Para as tarefas com resistência elástica do grupo GBIO, foi utilizada uma célula de carga (Interface, modelo SSM-ARS, 20kgf $\pm 10 \%$ ) específica do hardware utilizado no presente estudo.

A calibração de ambas as células de carga foi realizada aplicando-se forças conhecidas no eixo vertical às células. A partir das tensões elétricas geradas pelas forças aplicadas, os sinais eram processados em MatLab 6.5 (Mathworks; Natick, MA, USA) e uma curva de calibração foi traçada para cada célula.

A calibração do eletrogoniômetro confeccionado no próprio Laboratório de Processamento de Sinais Biológicos - UnB foi realizada acoplando-o a um goniômetro analógico nos ângulos de 20, 30, 50, 60, 70 , 90, 110, 130, 150, 170 e 180 graus. O 
processamento desses sinais foi feito em ambiente MatLab 6.5 (Mathworks; Natick, MA, USA) com rotinas específicas desenvolvidas para o instrumento.

\subsubsection{Avaliação Antropométrica}

Para caracterizar a amostra, foram utilizadas as medidas antropométricas de massa e estatura corporal, definidas da seguinte forma:

- Massa corporal: é o conjunto de matéria orgânica e inorgânica que compõe os diferentes tipos de tecidos e elementos corporais (Guedes e Guedes, 2006). Para mensuração da massa foi utilizada uma balança eletrônica digital (Líder Balanças®, modelo $P 180 M)$ com resolução de 100 gramas.

- Estatura: refere-se a distância entre dois planos que tangenciam o vértex e a planta dos pés com o indivíduo em pé, em apnéia inspiratória máxima (Guedes e Guedes, 2006). Foi utilizado um estadiômetro (Sanny®) com resolução de um milímetro.

\subsubsection{Contração Voluntária Isométrica Máxima}

A aquisição da contração voluntária isométrica máxima (CVIM) do dos flexores de cotovelo deu-se com o voluntário sentado em uma cadeira com encosto específico para o braço e com o cotovelo fletido a 90 graus (figura 7). Para medir tal angulação foi usado um goniômetro analógico (TTK, modelo 1216).

A célula de carga (AEPH do Brasil Indústria e Comércio Ltda., modelo TS, 50kg $\pm 10 \%$ ), ficava acoplada ao pé direito da cadeira e tinha uma alça afixada em sua extremidade por uma corrente de ferro inextensível como ilustra a figura 7. Essa alça era ajustada para que o sujeito conseguisse manter os 90 graus de flexão de cotovelo e simultaneamente imprimir sua força isométrica máxima durante cinco segundos em duas tentativas com dois minutos de intervalo de recuperação em cada (Melchiorri et al., 2011). Foi usado o maior valor de força e seu sinal processado por um algoritmo 
específico desenvolvido em MatLab 6.5 (Mathworks; Natick, MA, USA) a fim estimar o valor de $30 \%$ da CVIM.

Figura 8 - Aquisição da contração voluntária isométrica máxima (CVIM).

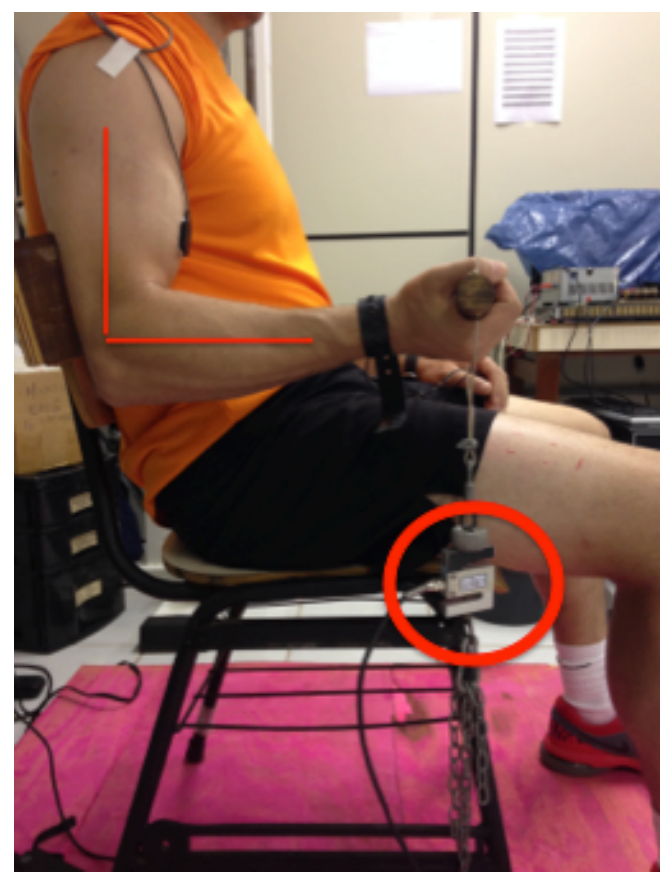

Em destaque a célula de carga e o ângulo do cotovelo.

\subsubsection{Dispositivo de Biofeedback}

O equipamento para o controle de carga em exercícios com resistência elástica e biofeedback (figura 8) controla, monitora e determina as faixas de cargas, aparentes em um display, em que o sujeito deverá executar durante o protocolo de exercício. Tal equipamento é constituído por um dinamômetro com um sistema eletrônico embarcado acoplado a uma célula de carga e possui registro de patente junto ao Instituto Nacional da Propriedade Industrial (INPI) com o número de registro BR 1020140072322 e de titularidade da Fundação Universidade de Brasília (FUB).

Tal dispositivo foi criado como intuito de prover controle objetivo em exercícios com implementos elásticos e possibilita que variáveis espaço-temporais sejam convertidas pelo sistema otimizando o controle de intensidade (Andrade, 2014). 
O sistema eletrônico é composto por uma central de condicionamento e aquisição, que realiza o processamento digital do sinal oriundo de um sensor de força acoplado ao equipamento, uma central de processamento e o biofeedback sonoro e visual que garante a integração das informações oriundas deste sensor.

Seu funcionamento depende de três etapas:

1. Exercício físico praticado pelo usuário e a quantidade de força aplicada sobre o implemento elástico;

2. A aquisição dos dados relacionados a esta quantidade de força e o processamento destes de acordo com as variáveis selecionadas pelo usuário no dispositivo;

3. Fornecer o feedback ao usuário sobre a execução de seu movimento e intensidade programada.

Para configurar o valor referente a $30 \%$ da CVIM no equipamento com biofeedback, o avaliador utilizou o arredondamento do valor inteiro imediatamente superior ou inferior quando necessário, já que o dispositivo possuía uma escala unitária em quilos. Por exemplo, se o valor de 30\% da CVIM do indivíduo em teste era de $7,3 \mathrm{~kg}$, o dispositivo era programado para $7 \mathrm{~kg}$ durante as tarefas com resistência elástica. Caso o valor fosse maior ou igual a $7,5 \mathrm{~kg}$, o dispositivo era programado para iniciar a faixa de intensidade com $8 \mathrm{~kg}$.

Figura 9 - Equipamento de controle de carga para resistência elástica com biofeedback ajustado para as tarefas feitas com implemento elástico no GBIO.

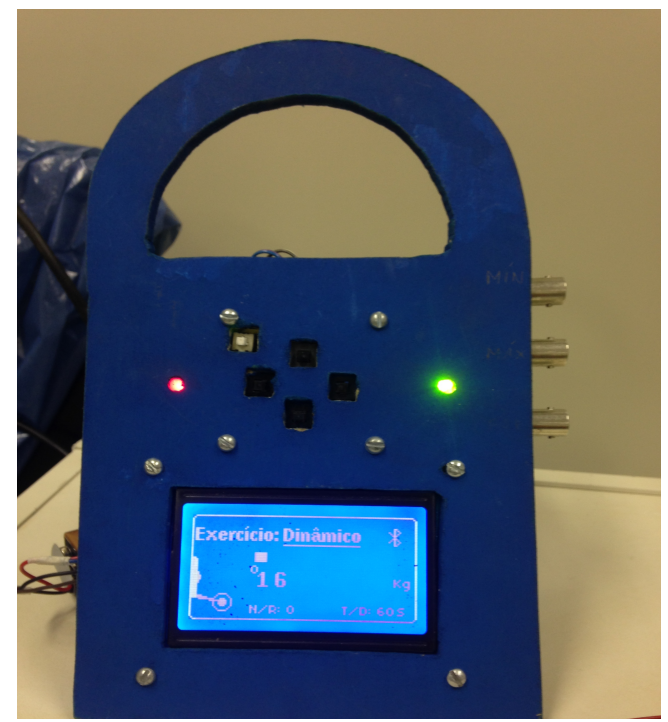




\subsubsection{Equipamento de Resistência Elástica}

A marca Elastos $®$ possui um kit com sete elásticos de cores e espessuras diferentes que indicam sua intensidade (figura 9). Quanto maior a espessura, maior deve ser a força imposta para se atingir a mesma deformação elástica. São eles na ordem de intensidade: amarelo, vermelho, verde, azul, preto, uva, ouro.

Devido às características da resistência elástica determina-se apenas uma faixa onde a carga objetivada é atingida e não ao longo de todo o movimento como ocorre na resistência fixa (Melchiorri et al., 2011).

Figura 10 - Kit de elásticos e acessórios da marca Elastos $®$ utilizados no presente estudo.

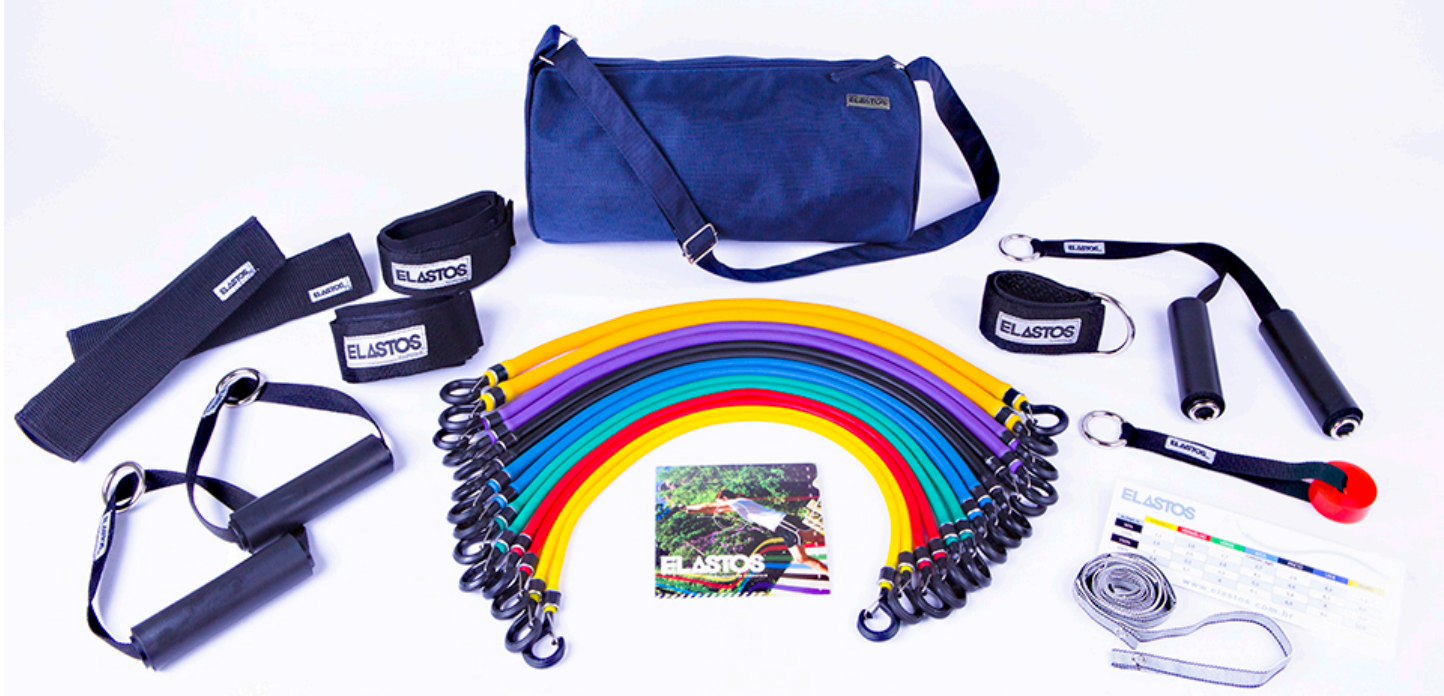

A escolha da resistência elástica baseada na carga de $30 \%$ da CVIM foi determinada por meio de um quadro de cargas desenvolvido por Martins et al. (2013) para o Elastos $®$. Nesta tabela é fornecido um valor quantificado em quilogramas força (kgf) para cada cor de elástico a partir do estiramento de 50\%, 100\%, 150\% e 200\% de seu tamanho inicial. Optou-se utilizar um estiramento de $100 \%$ devido a possível sensação de desconforto em se exercitar com uma grande deformação elástica dando ao voluntário uma impressão de que os elásticos poderiam arrebentar. 


\subsubsection{Aquisição dos Sinais de Eletromiografia}

Um eletrodo bipolar foi colado sobre a cabeça longa do músculo bíceps braquial a 1/3 da distância entre o acrômio medial e a fossa cubital, a partir da fossa cubital, de acordo com as recomendações do SENIAM (Hermens et al., 2000).

Para aquisição dos sinais eletromiográficos foi utilizado um eletromiógrafo Delsys ${ }^{\circledR}$ (modelo Bagnoli-2, Boston, Estados Unidos). Foram utilizados eletrodos ativos com pré-amplificação de $10 \mathrm{~V} / \mathrm{V}$ e filtro passa-faixa de $20 \mathrm{~Hz}$ a $450 \mathrm{~Hz}$. O ganho total do sinal foi de $1000 \mathrm{~V} / \mathrm{V}$, sendo $10 \mathrm{~V} / \mathrm{V}$ dos eletrodos e $100 \mathrm{~V} / \mathrm{V}$ do eletromiógrafo. A distância entre eletrodos foi de $1 \mathrm{~cm}$ com contatos de prata clorada $(\mathrm{Ag}-\mathrm{AgCl})$.

O sinal obtido pelo eletromiógrafo foi transferido para o computador por meio de uma placa análogo-digital de 12 bits (National Instruments, modelo PCI 6024E, Austin, Estados Unidos). A aquisição dos sinais foi realizada por meio da ferramenta computacional LabView e o processamento dos sinais foi realizado em MatLab versão 6.5 (Mathworks; Natick, MA, USA).

A amplitude do movimento foi controlada por um eletrogoniômetro anteriormente especificado no item 3.4.1. O sinal obtido foi utilizado para recorte da fase concêntrica do movimento considerando $180^{\circ}$ para extensão completa do cotovelo.

\subsubsection{O Processamento dos Sinais}

O sinal da SEMG foi inicialmente filtrado por um filtro Butterworth de quarta ordem com uma banda passante de $20 \mathrm{~Hz}$ a $500 \mathrm{~Hz}$ e correção no atraso de fase (De Luca, 1997). Um filtro passa-baixas com as mesmas características e com frequência de corte de $15 \mathrm{~Hz}$ foi utilizado para filtrar o sinal de força (Aagaard et al., 2000).

O sinal do eletrogoniômetro foi usado para recorte das bulhas do sinal eletromiográfico em cada repetição. As bulhas foram delimitadas considerando toda a 
fase concêntrica do movimento (figura 10). Foram descartadas das análises as primeiras e últimas contrações com a finalidade de minimizar possíveis problemas de manutenção da cadência comuns no início e no final das séries de exercício (Rocha Júnior, 2008).

Figura 11 - Representação do recorte do sinal eletromiográfico com base nas informações do eletrogoniômetro.

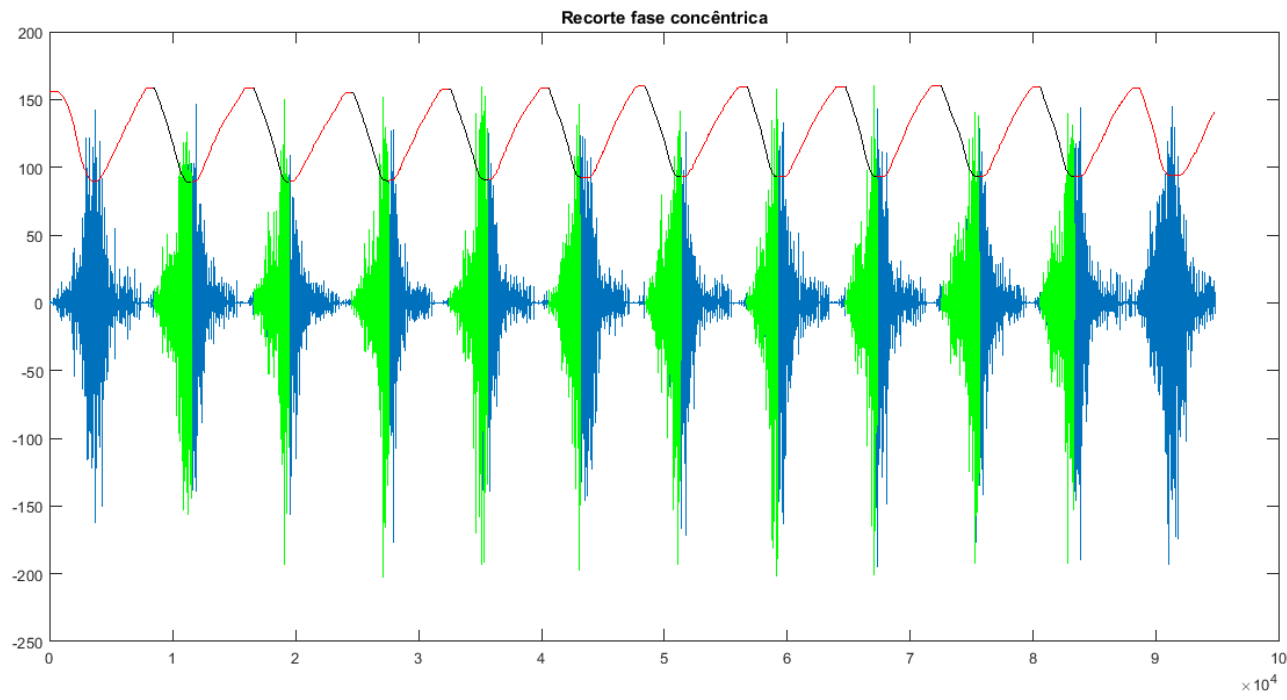

Em destaque (cor verde), a fase concêntrica analisada.

Após a normalização do sinal de EMG pelo sinal de força máxima obtido durante a CVIM, foram calculados, para cada bulha de cada repetição, o RMS e a FPMd conforme as equações 1 e 3 , respectivamente. A partir da FPMd referente a cada repetição, foram traçadas regressões lineares para indicar o comportamento de fadiga desencadeado pelo exercício. As inclinações das retas de regressão (coeficientes angulares) foram normalizados por seus valores iniciais (coeficientes lineares) para facilitar a comparação entre os voluntários e situações experimentais. Todo o processamento dos sinais foi feito por meio de rotinas especificas desenvolvidas no software MatLab 6.5 (Mathworks; Natick, MA, USA).

\subsection{Análise Estatística}

Elementos da estatística exploratória foram utilizados para identificar outliers e possíveis erros de digitação. As medidas de média e desvio padrão serviram para 
caracterização da amostra. Utilizou-se um Teste-t pareado nas comparações dos dados antropométricos (massa, estatura e IMC) e de idade.

Para verificação da normalidade dos dados utilizou-se o teste Shapiro-Wilk e para igualdade das variâncias o teste de Levene (Field, 2009). Após confirmada a normalidade, a comparação intra-grupos das variáveis eletromiográficas (RMS e FPMd) foram feitas por ANOVA's fatoriais de delineamento misto 2x3 [grupos (GBIO, GTRD) $x$ tarefas (Polia, Elástico-Inicio, Elástico-Meio)] (Field, 2009).

As comparações intra-grupos encontram-se descritas na tabela 1.

Tabela 1 - Resumo das comparações estatísticas realizadas intra-grupos.

\begin{tabular}{cc}
\hline GBIO & GTRD \\
\hline BIOi $\times$ BIOp & TRDi $\times$ TRDp \\
BIOm $\times$ BIOp & TRDm $\times$ TRDp \\
BIOi $\times$ BIOm & TRDi $\times$ TRDm
\end{tabular}

$\mathrm{BIOi}=$ tarefa biofeedback início; $\mathrm{BIOm}=$ tarefa biofeedback meio $; \mathrm{BIOp}=$ tarefa polia do grupo biofeedback; TRDi = tarefa tradicional início; TRDm = tarefa tradicional meio e TRDp = tarefa polia do grupo tradicional.

Devido a confirmação de não significância no teste de Levene utilizou-se o post-hoc de Turkey para localização das possíveis diferenças significativas (Field, 2009).

Análises gráficas para a variável de FPMd foram realizadas utilizando-se o método gráfico de Bland-Altman (1986). Tal ferramenta possibilita a comparação entre dois diferentes métodos e/ou determina se algum deles pode substituir aquele já estabelecido como padrão ouro (Myles et al., 2007). Desta forma, as comparações realizadas utilizaram a polia como o método padrão, pois essa possui um controle de carga fixo e conhecido.

Toda a análise estatística foi realizada com o software SPSS versão 20.0. 


\section{CAPÍTULO 4 - RESULTADOS}

Os dados para caracterização da amostra encontram-se descritos na tabela 2. Não foram encontradas diferenças significativas para esses valores entre os grupos estudados.

Tabela 2 - Descrição dos participantes que compuseram a amostra.

\begin{tabular}{lc}
\hline Variável & Média \pm desvio padrão \\
\hline $\mathrm{n}$ & 31 \\
Idade $(\mathrm{anos})$ & $29,03 \pm 5,99$ \\
Massa $(\mathrm{kg})$ & $81,81 \pm 8,65$ \\
Estatura $(\mathrm{cm})$ & $179,09 \pm 5,05$ \\
Índice de massa corporal $\left(\mathrm{Kg} / \mathrm{m}^{2}\right)$ & $25,52 \pm 2,55$ \\
\hline
\end{tabular}

Para os dados de eletromiografia, não houve qualquer perda de sinal. Observamos que a robustez do equipamento para aquisição de sinais eletromiográficos juntamente com todos os procedimentos prévios que envolvem a preparação da pele, seleção da amostra e minimização das interferências ambientais, foram levados em consideração durante todo o protocolo experimental.

Para os valores RMS, houve interação entre os grupos $(p=0,000)$ e efeito principal para as tarefas apenas dentro do grupo tradicional (GTRD).

No grupo com biofeedback (GBIO) não foram encontradas diferenças significativas para o RMS entre as tarefas com elástico BIOi $(p=0,426)$ e $\mathrm{BIOm}$ $(p=1,000)$ comparadas à polia (BIOp). Quanto comparadas entre $s i$, as tarefas com elástico início (BIOi) e meio (BIOm) também não apresentaram diferença significativa $(p=0,157)$. Observou-se que na tarefa com elástico e biofeedback para carga equivalente a $30 \%$ da CVIM no inicio do movimento, o valor RMS foi $9,85 \%$ maior que o encontrado na polia. Por outro lado, para a tarefa com elástico e biofeedback para a carga no meio do movimento, observou-se um decréscimo $0,4 \%$ do valor RMS comparado ao exercício realizado na polia.

No grupo tradicional (GTRD) foram encontradas diferenças significativas para o RMS entre as tarefas com elástico TRDi $(p=0,001)$ e TRDm $(p=0,000)$ comparadas à 
polia (TRDp). Quando comparadas entre si, as tarefas com elástico início (TRDi) e meio (TRDm) também não apresentaram diferença significativa $(p=0,254)$ como no GBIO. Para a tarefa com elástico e controle subjetivo de carga equivalente a $30 \%$ da CVIM no inicio do movimento, o valor RMS foi $25,36 \%$ menor que o encontrado na polia. Também na tarefa com elástico e controle subjetivo de carga para o meio do movimento, foi possível observar um decréscimo de $34,01 \%$ do valor RMS comparado ao exercício realizado na polia.

Para a FPMd não houve interação $(p=0,440)$ nem efeito principal para os grupos $(p=0,767)$ e tarefas $(p=1,000)$. Os valores médios e desvio padrão das inclinações das retas de regressão foram, para as tarefas polia, elástico início e elástico meio do GBIO: $-0,060 \pm 0,05 ;-0,085 \pm 0,15 ;-0,047 \pm 0,03$, respectivamente. Para o GTRD, os valores médios dessas inclinações foram: $-0,055 \pm 0,04 ; 0,029 \pm$ 0,52; $-0,054 \pm 0,05$ para polia, elástico início e elástico meio, respectivamente.

Todas as comparações obtidas pelo método gráfico proposto por Bland e Altman (1986) para os coeficientes angulares das retas de regressão da variável de FPMd apresentaram $96,7 \%$ de seus valores dentro do limite de concordância entre as tarefas executadas com elástico comparadas à polia. Esta abordagem estatística confirmou a boa concordância entre os métodos propostos a nível de fadiga muscular. As comparações estão representadas nas figuras de 11 a 14 .

Figura 12 - Gráfico Bland and Altman com os valores da FPMd das tarefas polia e elástico início do grupo GBIO.

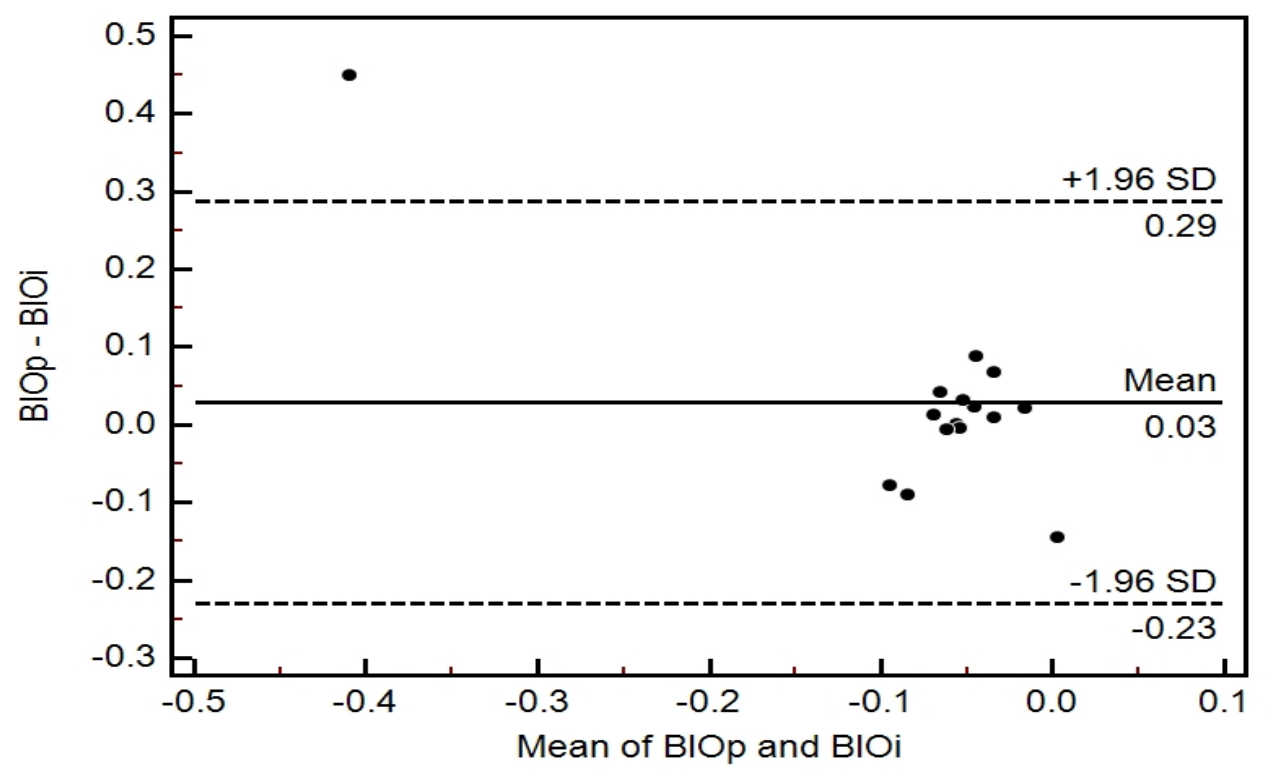


Figura 13 - Gráfico Bland and Altman com os valores da FPMd das tarefas polia e elástico meio do grupo GBIO.

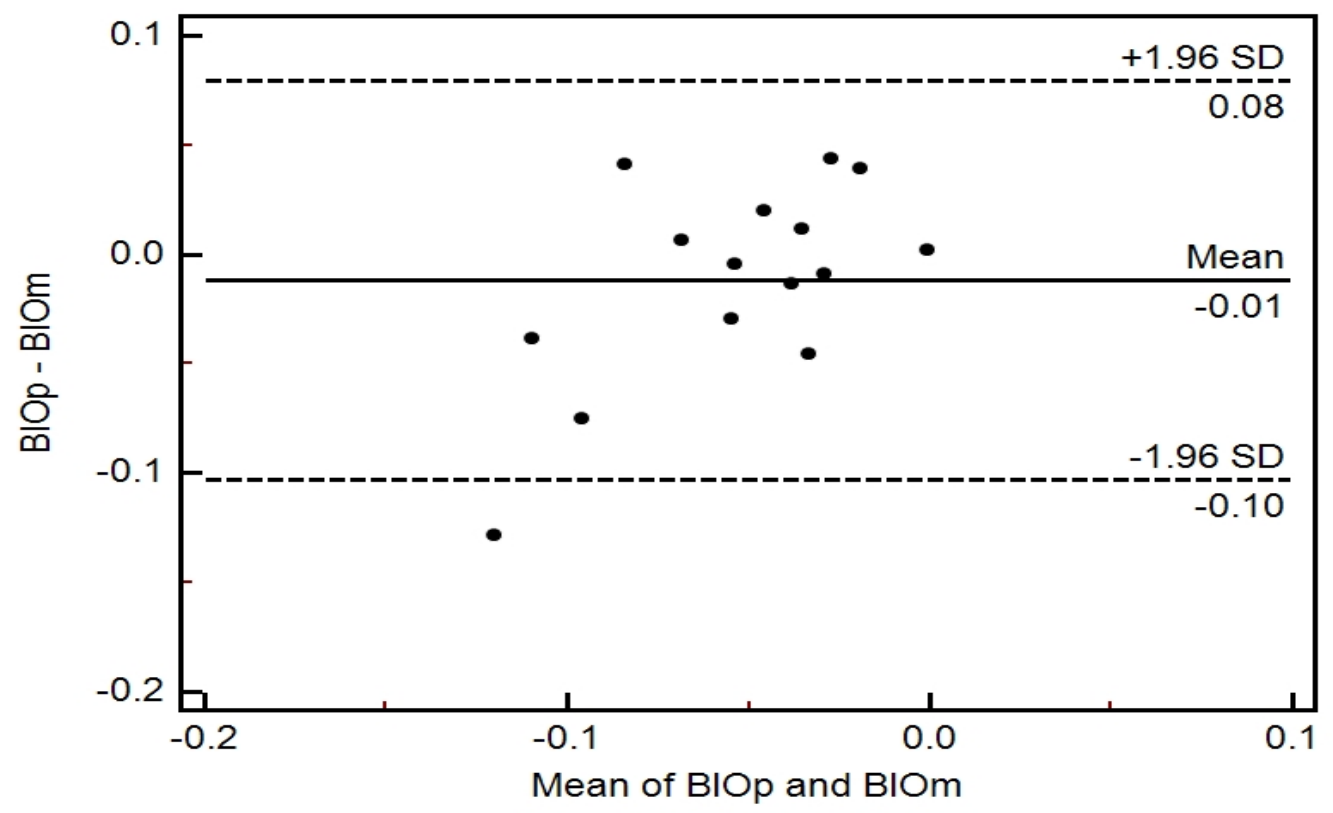

Figura 14 - Gráfico Bland and Altman com os valores da FPMd das tarefas polia e elástico início do grupo GTRD.

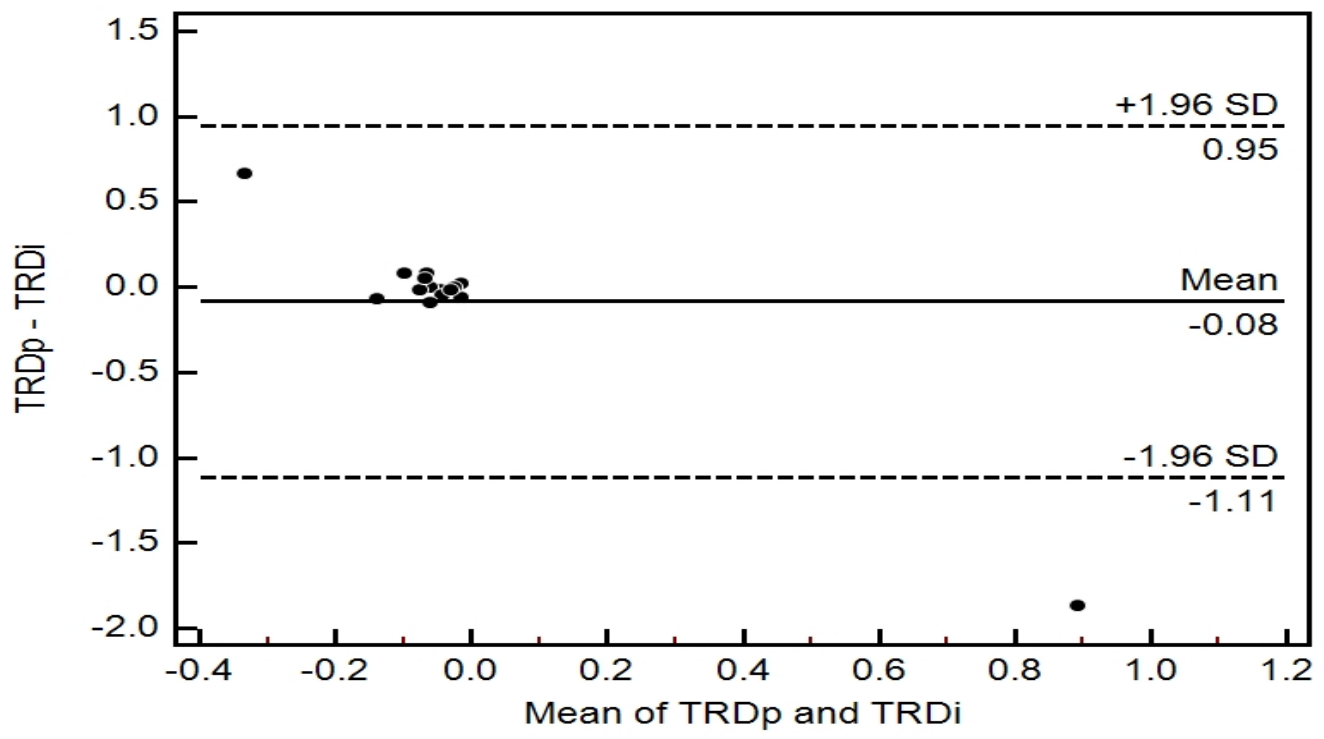


Figura 15 - Gráfico Bland and Altman com os valores da FPMd das tarefas polia e elástico meio do grupo GTRD.

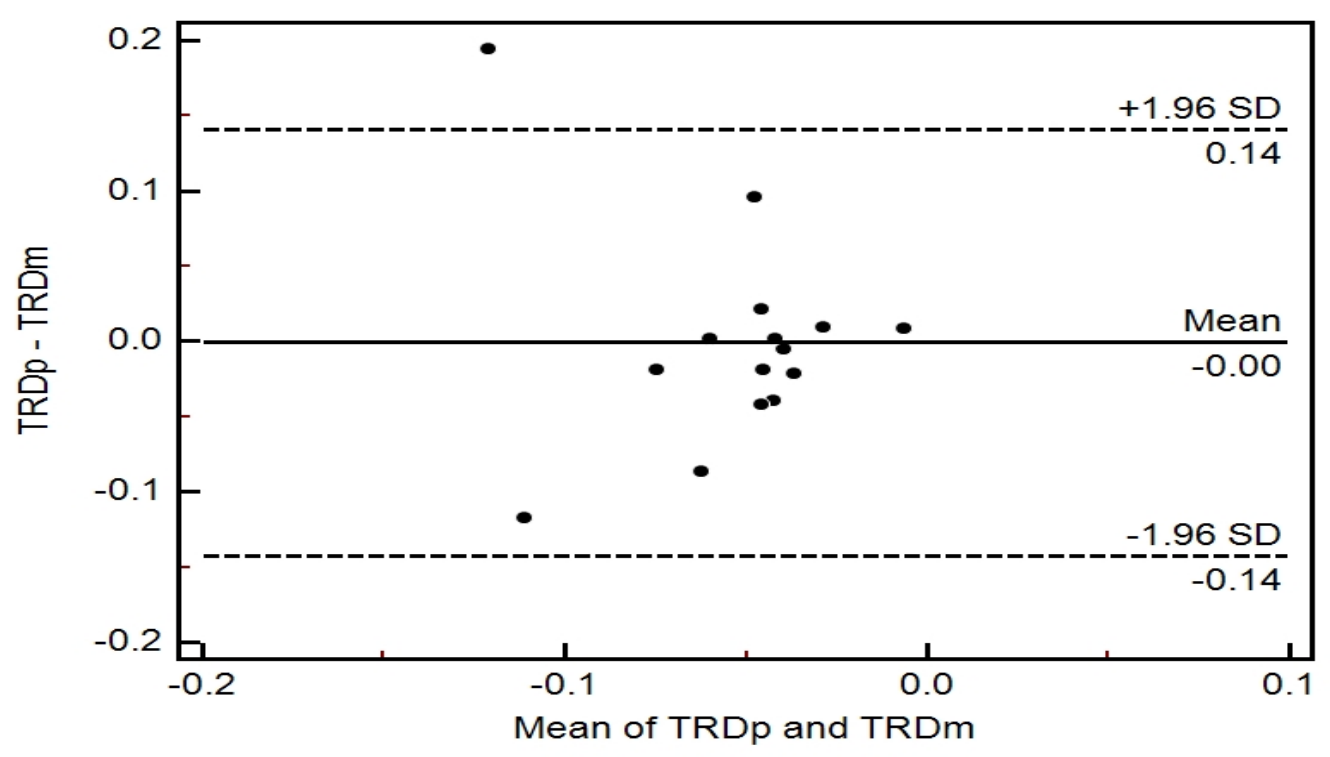




\section{CAPÍTULO 5 - DISCUSSÃO}

O objetivo do presente estudo consistiu em analisar o comportamento de parâmetros eletromiográficos durante o exercício de flexão de cotovelo realizado com resistência elástica sob controle objetivo ou subjetivo de carga. Esperava-se que o uso de um controle de carga objetivo para implementos elásticos com biofeedback modificasse o padrão de ativação muscular quando comparado à resistência constante e ao controle de intensidade baseado na percepção subjetiva de esforço.

Outra característica esperada era de que as tarefas com implementos elásticos controladas pela percepção subjetiva de esforço tivessem sua carga subestimada mesmo a amostra sendo caracterizada por praticantes ativos de treinamento resistido. Quanto à fadiga muscular, esperava-se que em nenhuma tarefa de nenhum dos dois grupos houvesse interferência desse parâmetro de forma a interromper a atividade ou não conseguir sustentar o ritmo imposto. No entanto, especulava-se que as tarefas com implementos elásticos pudessem ter um indicativo maior da mesma, principalmente no grupo com o dispositivo de controle de carga com biofeedback.

A análise da variação de parâmetros eletromiográficos por meio de retas de inclinação normalizadas é um procedimento comumente descrito na literatura (Farina et al. 2004c; Andrade, 2006; Rocha Júnior, 2008). O registro de sinais e o processamento de dados utilizados no presente estudo apresentam grandes semelhanças com os empregados por Sundstrup et al. (2012). Ainda que no estudo desses autores os mesmos tenham utilizado outros músculos de membros superiores que não o bíceps braquial, parâmetros de recrutamento (amplitude) e frequência do sinal eletromiográfico durante exercícios feitos com implementos elásticos com diferentes intensidades apresentam semelhança com parte dos resultados obtidos na dissertação.

O valor RMS, ou seja, a variável de análise no domínio do tempo do sinal eletromiográfico, está relacionada com o recrutamento de unidades motoras durante o exercício. O protocolo realizado no estudo procurou comparar tal variável com diferentes tipos de resistência em uma tarefa com número fixo de repetições $(12$, no 
caso) e com uma intensidade baixa (30\% da CVIM, no caso). Apesar de não ser exaustiva, a variável RMS, no grupo GBIO, apresenta valores maiores $(9,85 \%)$ na tarefa início (BIOi) quando comparados a tarefa polia (BIOp). Segundo Bilodeau et al. (2003), a possível causa dessa solicitação adicional de unidades motoras foi a compensação na perda de potencial contrátil das fibras inicialmente solicitas. Além disso, a resistência variável aumenta sua intensidade no decorrer da fase concêntrica onde a deformação elástica causada é diretamente proporcional ao aumento da carga (Martins et al., 2014). Assim, o uso do dispositivo de controle de carga na tarefa início (BIOi) garante que o exercício inicie com 30\% da CVIM mas a fase concêntrica finaliza-se com um valor maior do que a aquele iniciado. No caso da polia (BIOp), não há variação na carga e sim, apenas no torque em diferentes amplitudes do movimento (Leedham et al., 1995).

Apesar das diferentes e singulares características da resistência variável, o dispositivo de controle de carga e biofeedback utilizado no GBIO garantiu o controle da carga nas tarefas $\mathrm{BIOi}$ e $\mathrm{BIOm}$ pois estatisticamente não houve diferenças significativas no padrão de recrutamento muscular quando comparadas à tarefa na polia BIOp. Os resultados do presente estudo mostraram que a carga, mesmo que variável dos implementos elásticos, foi suficientemente a mesma para as três tarefas, atingindo o nível de intensidade proposto pelo protocolo (30\% da CVIM). Ao contrário, quando analisamos os valores RMS do grupo tradicional (GTRD), que teve controle subjetivo de carga, as diferenças significativas obtidas nos comparativos das tarefas que utilizam implementos elásticos (TRDi e TRDm) em relação a polia (TRDp) demonstram que a carga solicitada além de não ter sido atingida foi significativamente subestimada. Dessa forma, observou-se que o sistema eletrônico do dispositivo de controle de carga com biofeedback foi capaz de modificar o padrão de movimento dos voluntários durante o exercício praticado com resistência elástica e possibilitou que variáveis espaço-temporais fossem convertidas pelo sistema, otimizando o controle de intensidade. A ausência de um controle de carga para resistências variáveis já é relatada como um problema no estudo de Manning et al. (1989). Os resultados obtidos por esses autores mostraram que a utilização de da resistência elástica foi insuficiente para gerar mudanças significativas na força muscular isométrica de extensão do joelho comparada à resistência fixa de jovens adultos. Em suas argumentações, os mesmos sugerem que a ausência de resultados significativamente positivos para o 
uso da resistência elástica pode, entre outros fatores, estar associada ao controle de subjetivo de carga usado durante as intervenções. Com o mesmo argumento a respeito da ausência de controle de intensidade para resistência elástica, Martins (2013) justifica a ausência de significância em seus resultados após um treinamento físico de oito semanas feito com resistência variável em idosos. Assim, o dispositivo de controle de carga e biofeedback é capaz de modificar o padrão de movimento durante o exercício praticado com resistência elástica e possibilita que variáveis espaço-temporais sejam convertidas pelo sistema otimizando o controle de intensidade (Andrade, 2014).

Estudos prévios que comparam resistência elástica e resistência fixa e/ou investigam o comportamento da resistência elástica com diferentes intensidades, buscaram adaptar as variáveis de treinamento para essas diferentes resistências e avaliar aspectos fisiológicos e funcionais que resultam em ganhos de força e resistência à fadiga muscular (Azevedo, 2003; Anderson et al., 2008; Andersen et al, 2010; Melchiorri et al., 2011; Colado et al., 2011; Sundstrup et al., 2012; Calatayude et al.,2015). Sundstrup et al. (2012) investigaram estratégias de recrutamento dos músculos deltoide medial, trapézio superior, esplênio e infra-espinhal com o uso da SEMG durante o exercício de elevação lateral do ombro realizado com cargas máximas e submáximas usando implemento elástico. Os resultados encontrados mostraram que a maior ativação muscular (pico do valor RMS) ocorria quando os voluntários executavam o protocolo de carga submáxima comparado com o protocolo de carga máxima. Além disso, essa "máxima ativação" acontecia cerca de 3-5 repetições antes da falha concêntrica do movimento, ou seja, se o indivíduo realizasse 15 repetições, seu maior valor RMS ocorria por volta da décima repetição. Assim como no estudo de Sundstrup et al. (2012), a carga utilizada no presente estudo referiu-se a $30 \%$ da CVIM, ou seja, uma carga considerada submáxima. Esse resultado em comum permite reforçar a usabilidade do implemento elástico ao promover maiores níveis de ativação muscular em exercícios submáximos. Além disso, os resultados para a ativação muscular encontrados no presente estudo durante a atividade feita com resistência elástica e controle objetivo de carga (BIOi) apresentaram valores similarmente superiores comparado à polia $(9,85 \%)$.

Tratando-se de membros inferiores, Jakobsen et al. (2013) analisaram o sinal eletromiográfico dos músculos considerados motores primários e estabilizadores do 
exercício avanço com o uso de halteres e elástico. Foram usadas intensidades de $33 \%, 66 \%$ e 100\% referentes à carga de dez repetições máximas (10RM). Concluiu-se que o maior recrutamento muscular dos músculos do quadril e joelho ocorreu com o uso da resistência elástica em intensidade média (66\% de 10RM) quando comparada à baixa $(33 \%$ de $10 \mathrm{RM})$ e alta intensidades (100\% de 10RM). Ainda que o estudo de Jakobsen et al. (2013) tenha sido realizado com membros inferiores, seus achados vão de encontro aos apresentados no presente estudo no que diz respeito à maior ativação muscular para cargas de intensidade submáxima.

Ao comparar alterações dos níveis de força com treinamento utilizando diferentes resistências, Calatayud et al. (2015) verificaram ganhos similares para treinamento de cinco semanas do movimento de apoio no solo feito com resistência elástica e supino no aparelho Smith com uso de barra e anilhas. Os resultados desse estudo indicaram que o treinamento de 6RM para movimentos biomecanicamente similares, porém realizados com diferentes resistências, gerou ganhos de força semelhantes. Dessa forma, infere-se que ao se normalizar a intensidade dos exercícios, é possível se obter ganhos similares de força ao longo de um treinamento realizado com resistência elástica e fixa. Além disso, o exercício de apoio de solo com resistência elástica é versátil e pode ser executado em diversos locais e com diferentes ajustes de intensidade.

Segundo McMaster et al. (2009) utilizar diferentes tecnologias para o desenvolvimento de capacidades físicas pode ser uma alternativa prática para se evitar um platô dentro de um programa de treinamento. Anderson et al. (2008) propôs uma metodologia de treinamento para 44 atletas de basquete universitário que utiliza resistência fixa e variável comparada à um grupo controle. Dentre os exercícios propostos, apenas o agachamento e supino eram executados com resistência elástica no grupo experimental (uso de resistência fixa e variável). No grupo controle, todos os exercícios eram realizados com resistência fixa. Os resultados obtidos apontam uma interação entre os dois grupos com efeitos principais nos testes de força máxima entre os grupos experimental e controle. O grupo experimental, no qual utilizou as duas tecnologias (resistência fixa e variável), obteve maiores níveis de força após treinamento de sete semanas. 
No entanto, apesar dos benefícios anteriormente citados para o uso da resistência elástica no $\mathrm{TR}$, o controle subjetivo de carga continua sendo um dos maiores empecilhos para a popularização desse tipo de resistência. Na tentativa de normalizar a carga para efetuar um comparativo entre resistência fixa e variável, o estudo de Melchiorri et al. (2011) executou um protocolo de exaustão com contração dinâmica e isométrica da flexão de cotovelo, e, ao comparar as variáveis eletromiográficas pré e pós exaustão, não encontrou diferenças significativas. Os autores justificaram esse fato pelas adaptações neuromusculares necessárias para sustentar tarefas fatigantes serem as mesmas para ambas as resistências onde há uma queda da FPMd e aumento do valor RMS (Lindstrom et al., 1970, De Luca et al., 1979, Gerleman et al. 1989). Martins (2013) utilizou em seu estudo uma PSE validada para o uso de resistência elástica (Colado et al., 2012) com o intuito de monitorar a intensidade de um programa de treinamento de força com exercícios realizados com elástico em idosos. Seus resultados apontaram ausência de significância das variáveis de força muscular, tanto de membro superior quando inferior, quando comparado ao grupo controle. Mesmo utilizando a OMNI-RES, o autor relata em sua discussão o desafio e problemática da quantificação de carga para implementos elásticos.

No que diz respeito ao dispositivo para controle de carga proposto no presente estudo, são necessárias algumas considerações. Agregar os sinais de força juntamente com os sinais eletromiográficos pode ser uma ferramenta inferencial importante na tentativa de avaliar aspectos fisiológicos do sistema muscular e suas consequências a nível de desenvolvimento de capacidades físicas (Cannon et al., 2007; Melchiorri et al., 2011). Ensaios mecânicos têm sido retratados na literatura como forma de quantificar diferentes tipos de materiais elásticos. Martins et al. (2014) utilizou uma máquina de tração para quantificar diferentes deformações com elásticos comerciais em forma de tubos. Simoneau et al. (2001) comparou a variação de carga em elásticos em formato de banda e em formato de tubos e encontrou que apesar de serem do mesmo fabricante e material, estes proviam diferentes níveis de resistência para um mesmo nível de deformação. No entanto, a quantificação de carga por meio de máquinas de tração não garantem ao usuário um controle objetivo de intensidade e aplicabilidade no ambiente esportivo (Martins et al., 2013). Sendo assim, células de carga, também conhecidas como transdutores de força, como a usada no dispositivo 
proposto no presente estudo, podem ser consideradas uma alternativa para se obter um controle fidedigno.

Nesse sentido, o presente estudo inovou ao efetuar a monitoração e controle de intensidade com biofeedback durante exercício realizado com elástico e comparálo ao maquinário encontrado comercialmente.

No que se refere a variável de FPMd, não foram encontradas diferenças significativas entre as tarefas realizadas em ambos os grupos. Essa variável é considerada um indicativo da Fadiga Muscular Localizada (FML) e justifica-se pelo aumento do recrutamento por somação das unidades motoras e aumento da potência do sinal eletromiográfico nas baixas frequências, quando comparadas às altas, representando uma assinatura espectral associada à FML (Lindstrom et al., 1970, DeLuca et al., 1979). Dessa forma, o comportamento dessa variável em ambos os grupos confirma um padrão semelhante de fadiga para todas as tarefas solicitadas.

Este achado corrobora com Melchiorri et al. (2011) que investigou as modificações neuromusculares induzidas por exercício fatigante com resistência elástica comparada com maquinário de carga constante. O protocolo proposto pelos autores consistiam em contrações exaustivas isométricas e dinâmicas para o movimento de flexão do cotovelo. Apesar de não haver um consenso sobre a fadiga muscular em exercício dinâmico comparado com o isométrico com o uso da SEMG, os autores não encontraram diferenças significativas no padrão de fadiga para ambas contrações. Merletti e Parker (2004) e Bonato et al. (1996) associaram essas dificuldades à não estacionariedade do sinal mioelétrico. Em atividades dinâmicas os artefatos de movimento dos fios além da movimentação natural da pele e da musculatura ativa podem influenciar as análises espectrais da fadiga muscular. Além disso, o maquinário utilizado pelos autores foi confeccionado pelos mesmos para execução do movimento de flexão do cotovelo. Apesar de ser um movimento comum entre praticantes de treinamento resistido, todos os resultados são recorrentes da execução desse exercício em um equipamento de confecção única e não existente no mercado. Esse fato dificulta a aplicabilidade do estudo de Melchiorri et al. (2011) em diferentes ambientes de treinamento.

Com a finalidade de agregar valor à análise dos resultados apresentados pelo 
comportamento da FPMd, foi utilizado o método gráfico de Bland e Altman (1986). Nesse método buscou-se comparar a concordância entre as tarefas acerca do padrão de fadiga apresentado pelo exercício realizado na polia com as tarefas realizadas com resistência elástica e controle objetivo ou subjetivo de carga. Os gráficos apontaram (figuras 11 a 14) que para as comparações de FPMd realizadas, houve uma excelente concordância $(96,7 \%)$ entre os métodos (polia $x$ tarefas com elástico). Tal fato corrobora com o teste estatístico aplicado (ANOVA fatorial de delineamento misto) onde as comparações entre as inclinações das retas de regressão inferem que a fadiga apresentada em todas as tarefas para ambos os grupos foram semelhantes. Esse achado cancela a especulação de que as tarefas feitas com resistência elástica e controle objetivo ou subjetivo de carga possuem um maior potencial fatigante que a tarefa realizada na polia com a carga referente à 30\% da CVIM durante o exercício de flexão do cotovelo. Além disso, por se tratar de um protocolo de exercício com número limitado de doze repetições e com intensidade submáxima (30\% da CVIM), era esperada a não exaustão dos indivíduos participantes da pesquisa, justificando assim a similaridade no padrão de fadiga.

Considerando que as tarefas estudas possuem indicativo de fadiga muscular similares e são distintas quanto a curva de carga, uma com resistência fixa e outra elástica, os resultados sugerem que a adoção de exercícios intercalados entre essas duas modalidades, durante o processo de treinamento físico, podem se tornar uma alternativa para evitar um platô durante o treinamento (Stone et al., 2000). O exercício praticado com um único método resistivo tende a promover esse platô (Fleck \& Kraemer, 2006) e minimizar os resultados almejados (Stone et al., 2000).

Quanto ao nível de ativação muscular, a não significância entre as tarefas no grupo GBIO sugerem que ao se ter controle objetivo de carga em resistências variáveis a intensidade do exercício mantem-se suficientemente equivalentes que a tarefa que utiliza resistência fixa possibilitando ganhos similares de força e/ou resistência muscular (Calatayud et al., 2015). A ausência de controle quantitativo de carga para implementos elásticos impede o acompanhamento evolutivo do TR além da prescrição da carga necessária para se atingir o objetivo proposto (Tan, 1999; Fleck \& Kraemer, 2006; McMaster et al., 2009). O dispositivo de controle objetivo de carga para resistência elástica utilizado no presente estudo estimula o uso de implementos elásticos ao atingir níveis de ativação muscular semelhantes em 
exercício realizado com carga fixa. Em termos práticos, o uso do dispositivo reforça a portabilidade do elástico além de tornar-se uma alternativa de variação de treino de baixo custo comparado ao maquinário (Anderson et al., 2008; Melchiorri et al., 2011; Martins et al., 2014). 


\section{CAPÍTULO 6 - CONCLUSÕES}

O controle de carga subjetivo para exercícios com implemento elástico não garantiu que o nível de ativação muscular (RMS) fosse o mesmo para tarefas com resistência fixa. Além disso, ao se utilizar esse tipo de controle, mesmo em indivíduos familiarizados com treinamento resistido, a carga do exercício de flexão de cotovelo com elástico foi subestimada.

O nível de ativação muscular com controle objetivo de carga para resistência elástica com biofeedback foi semelhante à tarefa com resistência fixa. Esse controle permitiu melhor monitoramento da intensidade (carga) e manutenção do padrão de movimento no exercício de flexão do cotovelo.

Ainda, o comportamento da FPMd mostrou-se semelhante para ambos os grupos em todas a tarefas e evidenciou nível semelhante de fadiga.

Os resultados positivos encontrados com o uso de dispositivo para controle de carga com biofeedback ratificam o emprego de resistência elástica no desenvolvimento de diferentes capacidades físicas e possibilitam o uso de implementos variados no treinamento físico associado à portabilidade, ao baixo custo e ao melhor controle da técnica de movimento. São sugeridos ainda novos estudos envolvendo curvas de força, propostas metodológicas para comparação entre diferentes tipos de resistência e efeitos crônicos do uso de implementos elásticos com controle de carga e biofeedback. 


\section{REFERÊNCIAS BIBLIOGRÁFICAS}

ACSM - American College of Sports Medicine. (2009). Position Statement: Exercise and physical activity for older adults. Medicine and Science in Sports and Exercise, 41 (7): 1510-1530.

AAGAARD P, SIMONSEN EB, ANDERSEN JL, MAGNUSSON P, DYHRE-POULSEN $P$. (2002). Increased rate of force development and neural drive of human skeletal muscle following resistance training. J Appl Physiol, 93(4):1318-26.

ALKNER BA, TESCH PA, BERG HE. (2000). Quadriceps EMG/force relationship in knee extention and leg press. Med Sci Sports Exerc., 32(2), 459-463.

ANDERS, C., BRETSCHNEIDER, S., BERNSDORF, A., \& SCHNEIDER, W. (2005). Activation characteristics of shoulder muscles during maximal and submaximal efforts. Eur J Appl Physiol, 93(5-6), 540-546.

ANDERSEN LL, ANDERSEN CH, MORTENSEN OS, POULSEN OM, BJOMLUND IBT, ZEBIS MK. (2010). Muscle activation and perceived loading during rehabilitation exercises: comparison of dumbbells and elastic resistance. Physical Therapy, 90:538549.

ANDERSON, CE; SFORZO GA; SIGG, JA. (2008). The Effects of Combining Elastic and Free Weight Resistance on Strength and Power in Athletes. Journal of Strength and Conditioning Research, 22(2):567-574

ANDRADE MM, TELES FS, ROCHA VA, MARTINS WR, OLIVEIRA, RJ, Inventores; (2014) Fundação Universidade de Brasília (FUB); cessionário. Sistema de Biofeedback para a Prática de Exercícios Resistidos com Sobrecarga Elástica. Brasil, Patente BR 1020140072322.

ANDRADE MM. (2006). Análise tempo-frequência de sinais eletromiográficos para avaliação de fadiga muscular em cicloergômetro. Tese de Doutorado, ENE/UnB.

AZEVEDO, FM. (2003). Estudo da força e da atividade elétrica gerada pelo músculo quadríceps femoral submetido à exercícios com resistência elástica. Dissertação de Mestrado, Bioengenharia/USP São Carlos.

BILODEAU M, SCHINDLER-IVENS S, WILLIAMS DM, CHANDRAN R, SHARMA SS. (2003). EMG frequency contente changes with increasing force during fatigue in the 
quadriceps femoris muscle of men and woman. J Electromyogr Kinesiol, 13(1), 8392

BLAND, JM; ALTMAN, DG. (1986). Statistical methods for assessing agreement between two methods of clinical measurement. Lancet., i:307-310

BONATO P, GAGLIATI G, KNAFLITZ M. (1996) Analysis of myoeletric signals recorded during dynamics contractions. Engineering in Medicine and Biology Magazine, IEEE, 15(6), 102-11.

BOTTARO M RA, OLIVEIRA RJ. (2005). The effects of rest interval on quadriceps torque during an isokinetic testing protocol in elderly. Journal of Sports Science and Medicine, 4:285-90.

CALATAYUD J, BORREANI S, COLADO JC, MARTIN F, TELLA V, ANDERSEN LL. (2015). Bench press and push-up at comparable levels of muscle activity results in similar strength gains. Journal of Strength and Conditioning Research, 29(1):246253.

CANNON J, KAY D, TARPENNING KM, MARINO FE. (2007). Comparative effects of resistance training on peak isometric torque, muscle hypertrophy, voluntary activation and surface EMG between young and elderly women. Clin Physiol Funct Imaging, 27:91-100.

CARMO JC. (2003). Desenvolvimento de instrumentação dedicada e proposta de técnica de análise de fadiga em ciclistas utilizando transformada de wavelets. Tese de Doutorado, ENE/UnB.

CLANCY EA, MORIN EL, MERLETTI, R. (2002). Sampling, noise-reduction and amplitude estimation issues in surface electromyography. J Electromyogr Kinesiol, 12(1); 1-16.

COLADO JC, TRIPLETT NT. (2008). Effects of a short-term resistance program using elastic bands versus weight machines for sedentary middle-aged women. Journal of strength and conditioning research, 22(5):1441-8

COLADO JC, TRIPLETT NT, TELLA V, SAUCEDO P, ABELLAN J. (2009). Effects of aquatic resistance training on health and fitness in postmenopausal women. European Journal of Applied Physiology, 106: 113-122.

COLADO JC, GARCIA-MASSO X, PELLICER M, ALAKHDAR Y, BENAVENT J, CABEZA- RUIZ R. (2011). A comparison of elastic tubing and isotonic resistance exercises. International Journal of Sports and Medicine, 31: 810-817. 
COLADO JC, GARCIA-MASSO X, TRIPLETT TN, FLANDEZ J, BORREANI S, TELLA V. (2012). Concurrent validation of the OMNI-resistance exercise scale of perceived exertion with Thera-band resistance bands. Journal of Strength and Conditioning Research, 26(11): 3018-24.

CHAFFIN, DB. (1973) Localized Muscle Fatigue - Definition and Measurement. Journal of Occupational Medicine, 15(4): 346-354.

CHRISTENSEN H, SOGAARD K, JENSEN BR. (1995) Intramuscular and surface EMG power spectrum from dynamic and static contractions. J Electr Kinesiol, 5(1), 27-36.

DE LUCA, CJ. Physiology and Mathematics of Myoelectric Signal. (1979) IEEE Transactions on Biomedical Engineering, 26(6), 313-325.

DE LUCA, CJ. The use of surface electromyography in biomechanics. (1997) J Applied Biomechanics. 13, 135-163

DE LUCA, CJ. (2002). Surface electromyography detection and recording. DelSys Incorporated.

DE LUCA, CJ. (2003). Fundamental Concepts in EMG Signal Acquisition. DelSys Incorporated.

DE LUCA, CJ. (2006). Electromyography. Encyclopedia of Medical Devices and Instrumentation, 98-109.

ERFANIAN A, CHIZECK HJ, HASHEMI RM. (1994). Evoked EMG in electrically stimulated muscle and mechanisms of fatigue. Engineering in Medicine and Biology Society, in 16th Annual International Conference of the IEEE.

FARINA D, MERLETTI R, RAINOLDI A, BUINOCORE M. (1999). Two methods for the measurement of voluntary contraction torque in biceps brachii muscle. Medical Engineering \& Physics, 21, 533-540.

FARINA D, GAZZONI M, CAMELIA F (2004). Methods for estimating muscle fibre conduction velocity from surface electromyographic signals. Med Biol Eng Comput, 42(4), 432-445.

FARINA D, POZZO M, MERLO E, BOTTIN A, MERLETTI R (2004c). Assessment of average muscle fiber conduction velocity from surface EMG signals during fatiguing dynamic contractions. IEEE Trans Biomed Eng, 51(8), 1383-1393. 
FIELD, A. Descobrindo a estatística usando SPSS. (2009). Tradução Lorí Viali, 2 edição, Porto Alegre: Artmed, 688p.

FLECK SJ, KRAEMER WJ. (2004). Designing Resistance Programs. 3 edição, Champaign, IL: Human Kinectics, p.31.

FLECK SJ, KRAEMER WJ. (2006). Fundamentos do Treinamento de Força Muscular. Tradução Jerri Luiz Ribeiro, 3 edição, Porto Alegre: Artmed, 376p.

FULLER GD. Biofeedback: Methods and procedures in clinical practice. (1977). San Francisco: Biofeedback Press, 343p.

GERLEMAN, D. G., AND COOK, T. M. (1989) Instrumentation, in manual of surface electromyography for use in the occupational setting, DHHS Publication, US, pp. 81126.

HALL, SJ. Biomecânica Básica. (2000) 3ed. Rio de Janeiro, Guanabara Koogan, $415 p$.

HERMENS HJ, FRERIKS B, DISSELHORST-KLUG C, AND RAU G. (2000). Development of recommendations for SEMG sensors and sensor placement procedures. J Electromyogr Kinesiol, 10: 361-374.

HUNTER, GR; WETZSTEIN, CJ; MCLAFFERTY, CL; ZUCKERMAN, PA; LANDERS, KA; BAMMAN, MM. (2001). High-resistance versus variable-resistance training in older adults. Medicine \& Science in Sports Exercise; 33(10)1759-1764

JAKOBSEN, MD, SUNDSTRUP E, ANDERSEN CH, PERSSON R, ZEBIS MK, ANDERSEN LL. (2014). Effectiveness of hamstring knee rehabilitation exercise performed in training machine vc. Elastic resistance. Am J Phys Med Rehabil, 93(4).

KRAEMER WJ, ADAMS K, CAFARELLI E, DUDLEY GA, DOOLY C, FEIGENBAUM M. (2002). American College of Sports Medicine position stand. Progression models in resistance training for health adults. Med Sci Sports Exerc., 34(1), 364-380.

KONRAD, P. (2005). The ABC of EMG - A Practical Introduction to Kinesiological Electromyography. Noraxon Inc. USA, 1-60.

LEEDHAM JS, DOWLING JJ. (1995). Force-length, torque-angle and EMG-joint angle relationships of the human in vivo biceps brachii. Eur J Appli. Physiol, (70): 421-426.

LINDSTROM, L.; PETERSEN, I. (1970). Power spectrum analysis of EMG signals and Its application. In Desmedt JE (Ed): Computer-Aided Electromyography: Progress in Clinical Neurophysiology. Basel, Switzerland, Karger, v.10, p.5. 
MANNING, RJ; GRAVES, JE, CARPENTER DM; LEGGETT SH; POLLOCK ML. (1989). Constant vs Variable resistance knee extension training. Medicine and Science in Sports and Exercise, 22(3), 397-401.

MARTINS WR OR, CARVALHO RS, DAMASCENO V, SANTOS M. (2013). Elastic resistance training to Increase Muscle Strength in Elderly: A systematic review with meta-analysis. Archives of Gerontology and Geriatrics, 57(1): 8-15.

MARTINS WR. (2013) Efeitos do Treinamento de Curta Duração com Resistência Elástica sobre a Força e Massa Muscular de Idosos Destreinados. Tese de Doutorado.

MARTINS WR, CARVALHO RS, SILVA MS, BLASCZYK JC, ARAÚJO JA, CARMO JC, RODACKI ALF, OLIVEIRA RJ. (2014). Mechanical evaluation of elastic tubes used in physical therapy. Physiother Theory Pract, 30(3): 218-22.

MASUDA T, KIZUKA T, ZHE JY, YAMADA H, SAITOU K, SADOYAMA T. (2001). Influence of contraction force and speed on mucle fiber conduction velocity during dynamics voluntary exercise. J Electromyogr Kinesiol, 11(2), 85-94

MARCHETTI PH, DUARTE M. (2006) Instrumentação em Eletromiografia. Laboratório de Biofísica. Apostila.

MCARDLE, WD, KATCH, FI, KATCH, VL. (2008). Fisiologia do exercício: energia, nutrição e desempenho humano. $6^{a}$ edição, Rio de Janeiro: Ed. Guanabara Koogan.

MCMASTER, DT; CRONIN J, MCGUIGAN M. (2009) Forms of Variable Resistance Training. Strength and Conditioning Journal, 31(1): 50-64.

MELCHIORRI, G; RAINOLDI, A. (2011). Muscle fatigue induced by two different resistances: Elastic tubing versus weight machines. Journal of Electromyography and Kinesiology, 21(6): 954-959.

MERLETTI, R., DI TORINO, P. (1999). Standards for reporting EMG data. J Elec. Kines, 9(1): III-IV.

MERLETTI, R., PARKER, P. (2004). Electromyography: physiology, engineering, and noninvasive applications. [Hoboken, NJ]: IEEE/ John Wiley \& Sons.

MEZZARANE RA, ELIAS LA, MAGALHÃES FH, CHAUD VM E KOHN AF. (2014). Experimental and simulated EMG responses in the study of the human spinal cord. Electrodiagnosis in New Frontiers of Clinical Research. São Paulo, Chapter 4, 57-87. 
MORAS G, RODRÍGUEZ-JIMÉNEZ S, BUSQUETS A, TOUS-FAJARDO J, POZZO M, MUJIKA I. (2009). A metronome for controlling the mean velocity during the bench press exercise. Journal of strength and conditioning research, 23(3), 926-931.

MORITANI T, MURO M. (1987). Motor unit activity and surface electromyogram power spectrum during increasing force of contraction. Eur J Appl Physiol Occup Physiol, 56(3), 260-265.

MYLES, PS; CUI, J. (2007). Using the Bland-Altman method to measure agreement with repeated measures. British Journal of Anaesthesia, 99(3): 309-11.

OLIVEIRA AS, GONÇALVES M. (2009). Posiotioning during resistance elbow flexor exercise affects electromyographic activity, heart rate, and perceived exertion. Journal of Strength and Conditioning Research, 23(3), 854-862.

PEREIRA, MC. (2009). Relação de parâmetros eletromiográficos com a transição aeróbia-anaeróbia em ciclistas treinados. Dissertação de Mestrado.

PETERSON MD, RHEA MR, SEN A, GORDON PM. (2010). Resistance exercise for muscular strength in older adults: a meta-analysis. Ageing Res Rev, 9(3):226-37.

PRESTES J, DE LIMA C, FROLLINI AB, DONATTO FF, CONTE M. (2009). Comparison of linear and reverse linear periodization effects on maximal strength and body composition. Journal of Strength and Conditioning Research, 23(1), 266-274

ROBERTSON RJ, GOSS FL, RUTKOWSKI J, LENZ B, DIXON C, TIMMER J. (2003). Concurrent validation of the OMNI perceived exertion scale for resistance exercise. Medicine and science in sports and exercise, 35(2):333-41.

ROCHA JÚNIOR, VA. (2008) Respostas neuromusculares do músculo vasto lateral ao método da pré-exaustão adaptado. Dissertação de Mestrado.

ROSA DE SÁ AA, SOARES AB. Interface computacional 3D para biofeedback multimodal em tempo real. (2012). Revista Brasileira de Engenharia Biomédica, 28(4), 387-397.

SAKANOUE N, KATAYAMA K. (2007). The resistance quantity in knee extension movement of exercise bands (Thera-Band). Journal of Physical Therapy Science, 19: $287-291$.

SCHOENFELD, BJ. (2010). Mechanisms of muscle hypertrophy and their application to resistance training. Journal of Strength and Conditioning Research, 24(10), 2857-2872. 
SCHWANBECK S, CHILIBECK PD, BINSTED G. (2009). A comparison of free weight squat to smith machine squat using electromyography. Journal of Strength and Conditioning Research, 23(9), 2588-2591.

SIMONEAU GG, BEREDA SM, SOBUSH DC, STARSKY AJ. (2001). Biomechanics of elastic resistance in therapeutic exercise programs. The Journal of orthopaedic and sports physical therapy, 31(1):16-24.

SOARES, FA. (2013). Processamento de sinais eletromiográficos de superfície utilizando técnicas de processamento de imagens. Tese de Doutorado.

STEIB, S; SCHOENE, D; PFEIFER, K. Dose-response relationship of resistance training in older adults: a meta-analysis. (2010) Med Sci Sports Exerc, 42(5):902-14.

SUNDSTRUP E, JAKOBSEN MD, ANDERSEN CH, ZEBIS MK, MORTENSEN OS, ANDERSEN LL. (2012). Journal of strength and conditioning research, 26(7), p. 1897-1903.

TAN, B. (1999). Manipulating resistance training program variables to optimize maximum strength in men: a review. Journal of Strength and Conditioning Research,13(3), 289-304.

WEBSTER JG. (1984). Reducing motion artifacts and interference in biopotential recording. IEEE Trans Biomed Eng, 31(12), 823-826.

WELSCH EA, BIRD M, MAYHEW JL. (2005). Electromyography activity of the pectoralis major and anterior deltoid muscles during three upper-body lifts. Journal of Strength and Conditioning Research, 19(2), 449-452. 


\section{LISTA DE ANEXOS}

Página

ANEXO I - Termo de consentimento e livre esclarecimento (TCLE) ...................... 52

ANEXO II - Algoritmo de Calibração do Eletrogoniômetro..................................... 54

ANEXO III - Algoritmo de Corte dos Sinais pelo Eletrogoniômetro.......................... 56

ANEXO IV - Algoritmo de Cálculo das Variáveis Eletromiográficas (RMS e FPMd) 57

ANEXO V - Algoritmo de Cálculo do Espectro de Frequências do Sinal Eletromiográfico........................................................................................ 58 
ANEXO I - Termo de consentimento e livre esclarecimento (TCLE)

\section{TERMO DE CONSENTIMENTO E LIVRE ESCLARECIMENTO (TCLE)}

Caro participante, você está sendo convidado a participar voluntariamente de uma pesquisa na Universidade de Brasília intitulada "Proposição Metodológica Aplicada a Exercícios Físicos com Resistência Elástica”.

Atualmente, tem crescido o uso de elásticos para prática de exercícios físicos, muitas vezes bem parecido com o treinamento tradicional com pesos. Mas, diferentemente do que ocorre com os pesos, o controle da carga dos exercícios com elásticos é inexistente ou feita através da percepção do aluno e/ou do professor. Assim, a falta de controle da carga nem sempre garante ganhos no treinamento ou até mesmo se o exercício está sendo executado na intensidade proposta. Com isso, o objetivo desta pesquisa é propor uma metodologia para exercícios feitos com elásticos através de um aparelho de ajuste da carga durante a execução dos exercícios e comparar parâmetros musculares entre resistência elástica com a polia.

Espera-se que os exercícios com controle de carga em elásticos sejam capazes de acentuar os benefícios do exercício, assim como proporcionar controle de execução e garantia da intensidade, assim como ocorre nos exercícios com máquinas de musculação.

Por favor, leia com atenção as informações contidas neste termo antes de tomar qualquer decisão sobre sua participação como voluntário. Todos os esclarecimentos que julgar necessário antes e durante a pesquisa poderão ser feitos diretamente para o pesquisador responsável. Da mesma forma, você terá direito de recusar a responder questões que lhe tragam constrangimentos. A sua participação é voluntária e você terá plena e total liberdade para desistir do estudo a qualquer momento, sem que isso acarrete em qualquer prejuízo para você. Todas as informações relacionadas a pesquisa são confidenciais e qualquer informação divulgada em relatório ou publicação será feita sob forma codificada, para que seu sigilo seja mantido. Os pesquisadores garantem que seu nome não será divulgado sob hipótese alguma em qualquer publicação.

A pesquisa envolve a realização de 02 (dois) testes: $\left(1^{\circ}\right)$ avaliação da contração voluntária isométrica máxima do movimento de flexão de cotovelo e $\left(2^{\circ}\right)$ execução de um protocolo de 12 repetições do movimento de flexão do cotovelo com dois tipos de resistência: polia e elástico. Essa etapa irá durar de 01 dia, ou seja, você 
precisará comparecer apenas um dia no laboratório de coletas.

Toda a pesquisa será realizada na Universidade de Brasília, localizada no Campus Universitário Darcy Ribeiro, Brasília, DF - CEP 70910-900 e, especificamente no Laboratório de Processamento de Sinais Biológicos e Controle Motor da Faculdade de Educação Física. Esse termo de consentimento encontra-se redigido em duas vias, sendo uma para o participante e outra para o pesquisador, e deve conter a rubrica dos mesmos em cada uma das folhas. Em caso de dúvidas você pode entrar em contato com o pesquisador responsável, Profa. Fernanda Teles, pelo telefone: 61-9961-4907; ou pelo e-mail: fernandasteles@hotmail.com. Você também pode entrar em contato direto com o Comitê de Ética em Pesquisa da Faculdade de Ciências da Saúde da Universidade de Brasília pelo telefone: (61) 3107-1947; ou pelo e-mail: cepfs@unb.br.

Nome / assinatura

Pesquisador Responsável

Brasília, de de 
ANEXO II - Algoritmo de Calibração do Eletrogoniômetro

clear all

close all

clc

cd '/Users/sidneiteles/Fernanda/Faculdade_UnB/MESTRADO/dados mestrado/Coleta New 26-02-15';

fs $=2000$;

v_color = ['bkrgymcbkrgymcbkrgymcbkrgymcbkrgymcbkrgymc'] ;

$\%$ INCLUIR INTEIROS PARA DIVISAO

clc

sit $=\{[$ 'gtrdm'] ['gtrdi'] ['polia']\}; \%Estabelece situações experimentais

for $i=1$ : length(sit);

c_load $=$ ['load suj19_', sit $\{i\}, '$.txt']; \%Carrega sinais

end eval (c_load);

for $i=1$ : length(sit);

C_filt1 = ['suj19_', sit $\{i\},{ }_{-}$filt $(:, 1: 2)=$ butter_low(suj19_', sit $\{i\}, '(:, 1 \overline{1} 2)$, fs $) ; ']$; \%Filtra sinais de força e goniômetro

eval(c_filt1);

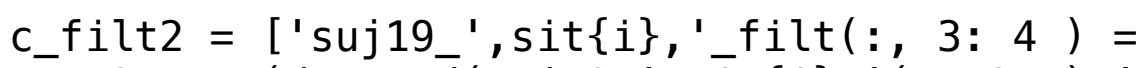

butter4_20_500(detrend( $\operatorname{suj} 19 \_', \operatorname{sit}\{i\}, '(:, 3: 4)$, ''constant''), fs); ']; $\%$ Filtra sinais de emg

eval(c_filt2);

end

goni1 $=[2030: 20: 170180] ; \quad \%$ Estabelece vetores do goniômetro

for $i=1$ : length(goni1);

goni2\{i\}= num2str(goni1(i));

end 
for $i=1$ : length(goni2);

C_load $=$ ['load calgoni',goni2\{i\},'.txt']; \&Carrega sinais eval (c_load);

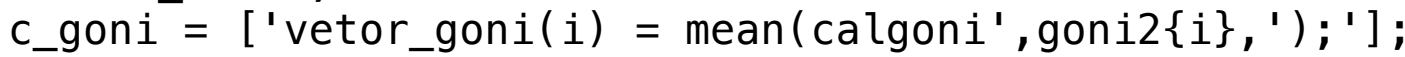

end eval(c_goni);

\%Carrega dados do goni

vetor_goni_cal $=\left[\begin{array}{llllllllll}20 & 30 & 50 & 70 & 90 & 110 & 130 & 150 & 170 & 180\end{array}\right]$;

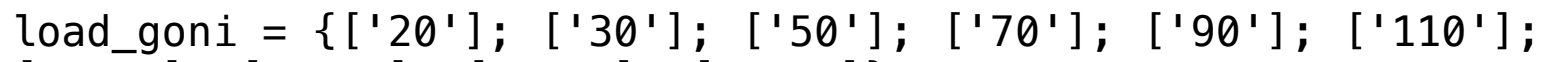

['130']; ['150']; ['170']; ['180']\};

for $i=1$ : length(load_goni);

comando_load $=[$ 'cal_goni $\{i\}=$

load(''calgōni', load_goníi\}\},'.txt' '); '];

eval (comando_load);

comando_corte $=[$ 'calgoni', load_goni $\{i\}, '=$

calgoni', load_goni\{i\}, '(500:1000); '];

eval (comando_corte);

comando_filt $=$ ['tensao_goni $(i)=$

mean(butter_low(calgoni', load_goni\{i\},', fs));'] ;

eval (comando_filt)

end

॰Calibração goni

$p=$ polyfit(tensao_goni, vetor_goni_cal, 1$)$;

reta_calibrada $=\operatorname{polyval}(p$, tensao_goni $)$;

reta $=($ vetor_goni_cal $-p(2)) / p(1)$;

reta_plot $=$ polyval $(p$, reta $)$;

plot(reta_calibrada, ' $r *-'$ );

hold on;

plot (reta_plot, '*-') ;

pause;

close; 
ANEXO III - Algoritmo de Corte dos Sinais pelo Eletrogoniômetro

\%Corta os sinais;

bulhas_gtrdi_angulo = fases_goni_fe_angulo(goni_cal_gtrdi, suj19_gtrdi_filt $(:, 3))$;

title('GtrdI CORTADO PELO ÂNGULO');

figure;

bulhas_gtrdm_angulo = fases_goni_fe_angulo(goni_cal_gtrdm, suj19_gtrdm_filt $(:, 3))$;

title('GtrdM CORTADO PELO ÂNGULO');

figure;

bulhas_polia_angulo = fases_goni_fe_angulo(goni_cal_polia, suj19_polia_filt $(:, 3))$;

title('POLIA CORTADO PELO ÂNGULO'); 
ANEXO IV - Algoritmo de Cálculo das Variáveis Eletromiográficas (RMS e FPMd)

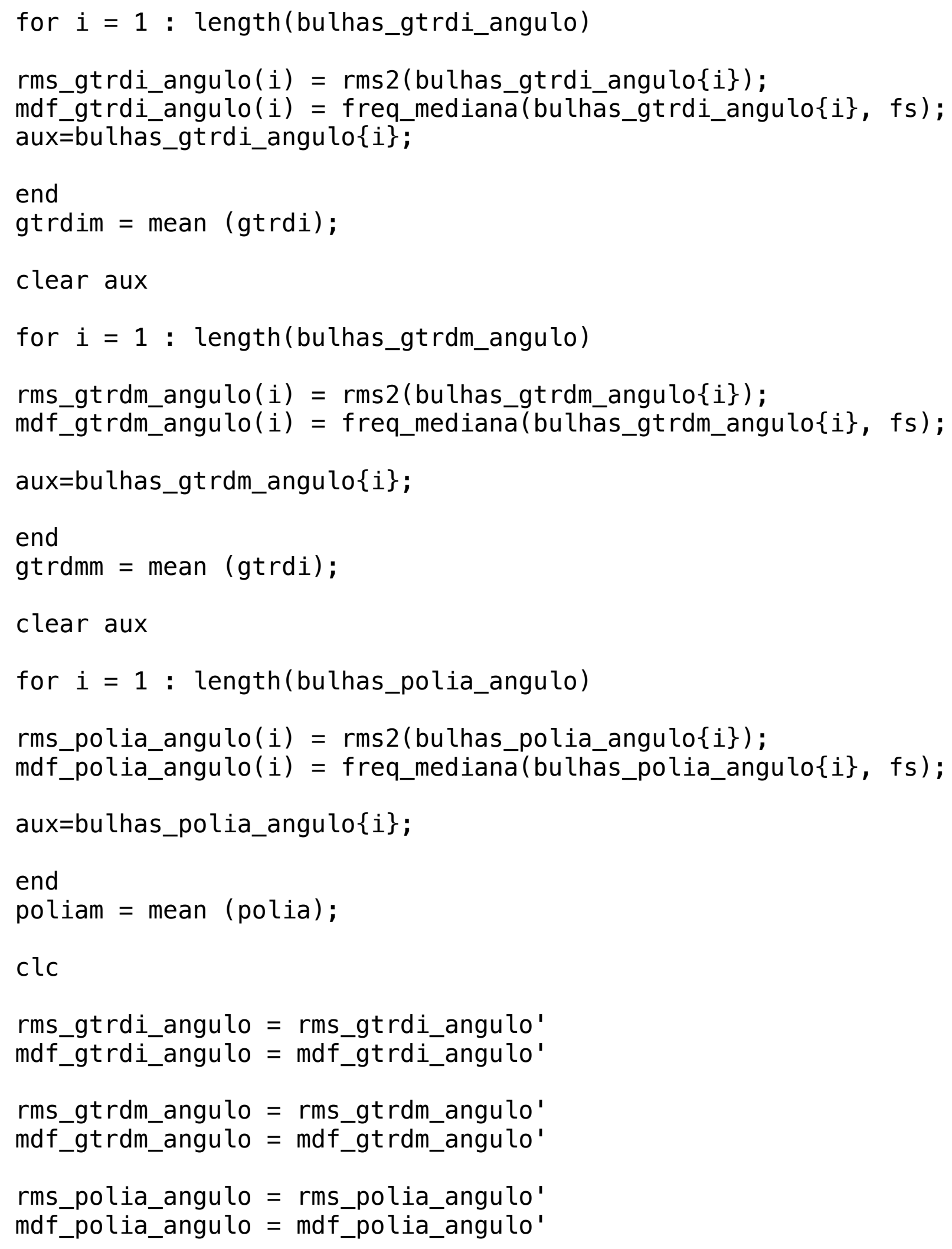



ANEXO V - Algoritmo de Cálculo do Espectro de Frequências do Sinal
Eletromiográfico

pause;

close all;

for $i=1$ : length(sit);

comando_freq $=[$ 'freq $($ suj19_', sit $\{i\}, '$ filt $(:, 3)$, fs, v_color(i));']; \%Filtra sinais de força e goniômetro

eval (comando_freq);

comando_title $=$ ['title(''Resposta em frequência do sinal Situação ', sit $\{i\}, '$ ' '); '] ;

eval(comando_title);

pause;

close;

end 